\title{
$\begin{array}{ll}\text { Research Square } & \text { Preprints are preliminary reports that have not undergone peer review. }\end{array}$ or referenced by the media as validated information. \\ Fe doped $\mathrm{TiO}_{2}$ catalyst synthesis using ultrasound and subsequent application for photocatalytic oxidation
}

\section{Valarmathi Mahendran}

Institute of Chemical Technology Department of Chemical Engineering

Parag Ratnakar Gogate ( $\sim$ pr.gogate@ictmumbai.edu.in )

Institute of Chemical Technology

\section{Research Article}

Keywords: Fe doped TiO2, co-precipitation, ultrasound, process intensification, photocatalytic oxidation

Posted Date: April 19th, 2021

DOI: https://doi.org/10.21203/rs.3.rs-339673/v1

License: @ (i) This work is licensed under a Creative Commons Attribution 4.0 International License. Read Full License 


\section{Abstract}

Photocatalytic oxidation has shown promise as alternative technique to conventional techniques though lack of efficient catalyst is a major problem in commercial application. In the current work, a transition metal, $\mathrm{Fe}$ (iron), is doped into the $\mathrm{TiO}_{2}$ catalyst by coprecipitation method assisted by ultrasound with an objective to achieve reduced particle size and better characteristics. Optimization study for the parameters associated with the synthesis was performed resulting in the best conditions of ultrasonic power $(120 \mathrm{~W})$, irradiation time (30 min), temperature $\left(35^{\circ} \mathrm{C}\right)$ and Fe doping (0.4 mol\%). Using characterization techniques of Particle size analysis, XRD, FTIR, UV-Vis bandgap analysis and BET analysis, the comparison of the catalysts obtained using ultrasound assisted and conventional approach was performed. The particle size obtained by ultrasound assisted process (US catalyst) was $348 \mathrm{~nm}$ which is much lesser than size of catalyst prepared conventionally (CV catalyst) as $1069 \mathrm{~nm}$. XRD and FTIR analysis demonstrated the superiority of the US catalyst over the CV catalyst. The UV-Vis bandgap analysis established the reduction of bandgap from $3.2 \mathrm{eV}$ to $2.8 \mathrm{eV}$ due to doping of Fe. BET analysis showed the improvement of surface area from $19.413 \mathrm{~m}^{2} / \mathrm{g}$ to $40.603 \mathrm{~m}^{2} / \mathrm{g}$ due to the use of ultrasound. The photocatalytic oxidation of Acid Scarlet 3R dye was performed, where US catalyst showed $48.2 \%$ degradation, higher than the CV catalyst where degradation was $34 \%$. Overall the work has shown the methodology to obtain efficient catalyst based on doping of Fe and the effect of ultrasound also demonstrating better photocatalytic activity.

\section{Introduction}

Advances in technology have resulted in higher demands for water in the industries which also means that higher amount of wastewater is generated from the industries. An increase in the demand for effective water treatment has resulted in research into various oxidation processes for obtaining high efficiency. Wastewater generated by the industries has a huge amount of inorganic and organic soluble substances demonstrating high chemical oxygen demand (COD) and typically offering low degradability for biological oxidation (Jo and Tayade, 2014; Priyaragini et al., 2014; Forgacs et al. 2004; Mahvi et al. 2009; Galindo et al. 2001; Vautier et al. 2001). Adsorption, extraction and chemical oxidation are some of the other conventional methods of wastewater treatment that also have limitations such as specific applicability, lower efficiency and secondary pollutant formation (Gogate and Patil, 2015). The efficacy of the conventional processes is lower when it comes to presence of molecules having complex structure and also there is always need for developing advanced processes. Advanced oxidation process, which rely on the generation of hydroxyl radicals and its attack on the pollutants offer promise for treatment. The hydroxyl radicals $(\mathrm{OH})$ have a high oxidation potential of $2.81 \mathrm{~V}$ which is the strongest oxidant and hence can oxidize any compound that comes in contact with it in the wastewater. Photocatalysis, ozonebased oxidation, Fenton chemistry and cavitation are some of the AOPs (Musmarra et al. 2016) used for wastewater treatment. The hydroxyl radical generation can be enhanced based on the use of the strong oxidizing reagents like hydrogen peroxide $\left(\mathrm{H}_{2} \mathrm{O}_{2}\right)$, ozone $\left(\mathrm{O}_{3}\right)$, molecular oxygen $\left(\mathrm{O}_{2}\right)$, etc., either in the process itself or as a suitable intensification strategy (Divyapriya et al. 2016, Sood et al. 2015). The 
attack of hydroxyl radicals $(\mathrm{OH})$ on the recalcitrant organic pollutants can lead to the formation of smaller intermediates or complete mineralization to water and $\mathrm{CO}_{2}$. Among the different AOPs, photocatalytic oxidation have shown promise for commercial application mainly based on the requirement of ambient conditions and possibility of using solar light which can give an economical operation.

In the case of photocatalytic oxidation, any photocatalyst gets activated when it absorbs light and gives expected and efficient conversion of reactants into products based on the interactions with hydroxyl radicals and/or electrons offering high yield and reaction rate. Many recent studies propose $\mathrm{TiO}_{2}$ to be one of the most applicable and satisfactory photocatalysts for water treatment which offers noticeable advantages as being non-toxic, stable and chemically inert (Hsien et al., 2001; Ranjit and Viswanathan, 1997). The bandgap energy of $\mathrm{TiO}_{2}$ is $3.2 \mathrm{eV}$ and it requires a wavelength of $388 \mathrm{~nm}$ for excitation of an electron from the valence band to the conduction band which falls in the ultraviolet region (Gu et al. 2010; Huang et al. 2009). $\mathrm{TiO}_{2}$ is reported as a perfect catalyst for photocatalytic degradation of the organic contaminants in water, decolorization of dyestuff, etc. (Reddy et al. 2016; Bethi et al. 2016). However, due to the huge energy crisis, the use of natural solar light having a visible wavelength over artificial UV light is crucial. Some modification is required to reach the excitation at the wavelength above $388 \mathrm{~nm}$, and one such method of modification is doping of catalyst. Doping of catalyst also helps in avoiding the recombination of photo-generated electrons and holes which can provide higher effectiveness for enhanced rates of degradation (Peng et al. 2012; Rauf et al. 2011).

Transition metals doping is predominantly used to improve photocatalytic activity and reduce the recombination hole and electron (Kočí et al. 2012; Barakat et al. 2005). Iron $\left(\mathrm{Fe}^{+3}\right.$ ) has been noticed to be a good dopant for $\mathrm{TiO}_{2}$ as it has an atomic radius of $0.69 \AA$ which is almost equal to that of $\mathrm{Ti}^{+4}$ as $0.745 \AA$ which makes it convenient to integrate $\mathrm{Fe}^{+3}$ into the $\mathrm{TiO}_{2}$ matrix and also due to its stable halffilled $d^{5}$ configuration (Sood et al. 2015). When a small amount of metal doping is present, photogenerated holes and electrons are well separated which therefore increases the efficacy. $\mathrm{Fe}^{3+}$ traps the photogenerated holes and it forms $\mathrm{Fe}^{4+}$ reacting with $\mathrm{OH}$ radical on the surface, generating hydroxyl radicals and $\mathrm{O}^{2-}$ in the surface lattice of doped $\mathrm{TiO}_{2}$. Also, $\mathrm{Fe}^{4+}$ itself can react with photogenerated electrons and affect photocatalytic activity (Tong et al. 2008). A study on using Fe-modified $\mathrm{TiO}_{2}$ for the degradation of Reactive Brilliant X-3B azo dye reported that $0.1 \mathrm{wt} \%$ of iron doping showed a good photocatalytic degradation (Qi et al. 2005). It was also reported that excessive deposition of $\mathrm{Fe}$ on $\mathrm{TiO}_{2}$ lead to the formation of $\mathrm{Fe}(\mathrm{OH})^{2+}$.

Many research work on ultrasound-assisted synthesis reported that it has a significant potential in improved nanomaterials synthesis (Sivakumar and Gedanken, 2004; Anandan and Ashokkumar, 2009). The employment of ultrasound waves through the liquid-based medium (solution for catalyst preparation) creates an alternate high and low-pressure zone in the liquid medium and thus shows different stages of cavitation. The cavity bubbles collapse leads to the formation of hot spots with a 
temperature of about $5000 \mathrm{~K}$ and a pressure of about $1000 \mathrm{bar}$. The cavitation energy released due to the ultrasound intensifies the micro-mixing which also improves mass transfer i.e., solute transfer rate and nucleation rate. The major reason for obtaining a lower size of the particle is due to the generation of cavitation bubbles and consecutive collapse which leads to fragmentation of the particle through microjets (Chen et al. 2011).

We now present brief literature review on the use of ultrasound for improved photocatalyst synthesis. Li et al. (2010) synthesized Fe doped $\mathrm{TiO}_{2}$ based on the ultrasound-assisted hydrothermal method for the degradation of methyl orange. Zhou et al. (2006) synthesized Fe doped $\mathrm{TiO}_{2}$ using the ultrasonicallyinduced hydrolysis method. Shirsath et al. (2013) studied the effect of ultrasound operating parameters affecting the particle size of the catalyst prepared based on the sol-gel synthesis process assisted by the ultrasonic horn. Huang et al. (2009) reported that the catalytic performance of a doped $\mathrm{TiO}_{2}$ photocatalyst depends on the amount of the dopant and the method by which the doping is carried out. Analysis of the literature revealed that there has been no study reporting the use of co-precipitation method and the effect of ultrasound on the same for the synthesis of Fe doped $\mathrm{TiO}_{2}$. Considering this, the importance of the present work is established.

In the current work, Fe doped $\mathrm{TiO}_{2}$ catalyst is synthesized based on the co-precipitation method. The irradiation system of the ultrasonic bath is chosen for the study so that there is no probability of tip erosion based on the indirect contact and hence there would not be any adverse effect on the quality of the synthesized catalyst (Ambati and Gogate, 2018). The main objective of the work is to investigate the effect of ultrasound in the synthesis of $\mathrm{Fe}$ doped $\mathrm{TiO}_{2}$ photocatalyst by the co-precipitation method so as to establish the improvement in the morphology and characteristics of the Fe doped $\mathrm{TiO}_{2}$. The work also focuses on the optimization of the sonication parameters so as to obtain conditions for the minimum particle size and optimum Fe doping. Characterization study of prepared photocatalyst was also performed to establish the effects of ultrasound and subsequently photocatalytic effect of the Fe doped $\mathrm{TiO}_{2}$ catalyst has been studied for dye decolorization application.

\section{Materials And Methods}

\subsection{Materials}

Titanium (IV) isopropoxide (98\%) was procured from Avra Synthesis Pvt Ltd. Commercial grade Urea was used whereas Ferric Nitrate nonahydrate $\left.\left[\mathrm{Fe}\left(\mathrm{NO}_{3}\right)_{3} 9 \mathrm{H}_{2} \mathrm{O}\right)\right]$ (98\%) was purchased from Thomas Baker, Mumbai, India. The Acid Scarlet 3R dye procured from Nilkanth Dyestuff industries was used as model pollutant. The distilled water used throughout the experiment was obtained from the Millipore distillation unit.

\subsection{Experimental methodology}




\subsubsection{Fe doped $\mathrm{TiO}_{2}$ synthesis by the ultrasound-assisted approach}

Iron doped $\mathrm{TiO}_{2}$ was synthesized by the co-precipitation method with the assistance of ultrasound. Initially, $0.4 \mathrm{~g}$ of urea was dissolved in $40 \mathrm{ml}$ of distilled water in which the calculated amount of Ferric Nitrate (as per the required loading of $0.2-1.2 \mathrm{~mol} \%$ of Fe) was added. Subsequently, $10 \mathrm{ml}$ of Titanium (IV) tetra-isopropoxide (TTIP) was added dropwise to the prepared urea and Ferric Nitrate solution under the stirring at $500 \mathrm{rpm}$. Soon after the addition of TTIP, the mixture was kept in the ultrasonic bath. After the reaction, the prepared solution was dried in a water bath at $80-90^{\circ} \mathrm{C}$ and calcined at $500{ }^{\circ} \mathrm{C}$ for $3 \mathrm{~h}$ in a muffle furnace. The obtained sample (referred as US catalyst) was then subjected to grinding before actual use. Figure 1 depicts the scheme of catalyst synthesis.

Experiments with the ultrasound were performed using a low-power ultrasonic cleaning bath (Dakshin Ltd., Mumbai, India). The ultrasonic bath used for the experiments had a stainless steel rectangular tank. The tank dimensions were $300 \times 150 \times 150 \mathrm{~mm}$. The surface area of the bath is $0.045 \mathrm{~m}^{2}$. At the bottom of the tank, there are five transducers arranged in a zigzag position. Ultrasonic bath operates at $22 \mathrm{kHz}$ and total power of 250 W (Moholkar et al. 2000; Rao and Rathod, 2015). The glass reactor (flat base with a diameter of $7 \mathrm{~cm}$ ) was placed at the center of the bath and the bath was filled with 4 liters of water used as coupling fluid. The schematic setup is shown in Fig. 2. In the case of ultrasound assisted approach, the effect of different parameters as the power of sonication, time of sonication, the temperature of the water bath and \% Fe doping on the catalyst size has been studied.

\subsubsection{Fe doped $\mathrm{TiO}_{2}$ synthesis by the conventional approach}

In this procedure, the Fe doped $\mathrm{TiO}_{2}$ was synthesized by the co-precipitation method. $0.4 \mathrm{~g}$ of urea was taken and dissolved in $40 \mathrm{ml}$ of distilled water in which the calculated amount of Ferric Nitrate was added for obtaining loading of $0.4 \mathrm{~mol} \% \mathrm{Fe} .10 \mathrm{ml}$ of TTIP (Titanium (IV) isopropoxide) was added dropwise to the prepared urea and Ferric Nitrate solution under condition of the stirring at $500 \mathrm{rpm}$. After the reaction, the prepared solution was dried in a water bath at $80-90^{\circ} \mathrm{C}$ and calcined at $500{ }^{\circ} \mathrm{C}$ for 3 hours inside the muffle furnace. The obtained sample was subjected to grinding and referred to as the conventionally prepared catalyst (CV catalyst).

\subsubsection{Fe doped $\mathrm{TiO}_{2}$ catalyst Characterization}

The particle size of the iron-doped $\mathrm{TiO}_{2}$ catalyst samples was analyzed using Malvern Zetasizer Nano S model. X-ray diffraction analysis of the catalyst was carried out using a powder X-ray diffractometer (Philips PW 1800). The diffraction patterns of the sample were obtained using radiation source of $\mathrm{Ni}$ filtered Cu-Ka radiation at wavelength $\lambda=1.5418 \AA$. The test was performed at room temperature. The XRay Diffraction patterns of the catalyst were recorded between the angles of $20^{\circ}$ to $80^{\circ}$ at a $2 \% \mathrm{~min}$ scanning rate. Match software was used to interpret the peaks and characterize the synthesized Fe doped 
$\mathrm{TiO}_{2}$ catalyst. FTIR spectra for the catalysts were also recorded using Perkin Elmer FTIR spectrometer (Paragon $1000 \mathrm{PC}$ ) with the wavenumber ranging from 500 to $4000 \mathrm{~cm}^{-1}$. The UV-Visible band gap spectra were observed using Agilent UV-Vis Cary 100 spectrophotometers between the range of 200 to $800 \mathrm{~nm}$. The BET surface analysis of the samples was performed using SMART SORB 92193 surface area analyzer. The adsorption and desorption study of the catalysts was also carried out using liquid nitrogen to find the specific surface area.

\subsubsection{Photocatalytic degradation of Acid Scarlet 3R dye}

To find the photocatalytic activity of the catalysts obtained with different amounts of Fe and using ultrasound-assisted and conventional approaches, photocatalytic oxidation experiments were performed. Experiments were carried out inside a UV chamber with two UV lamps (Phillips 8W TUV) operating at a dominant wavelength of $254 \mathrm{~nm}$. A Quartz beaker of $250 \mathrm{ml}$ capacity having a diameter of $68 \mathrm{~mm}$ and a height of $95 \mathrm{~mm}$ was used throughout the experiment. Two UV lamps were placed inside the chamber with one at the top and one on the side so that the light intensity is evenly distributed to the Quartz reactor. Figure 3 shows the sketch of the photocatalytic reactor. All the experiments were performed using a fixed volume of dye solution as $200 \mathrm{ml}, 50 \mathrm{ppm}$ of dye concentration with $0.4 \mathrm{~g} / \mathrm{L}$.

The degradation of dye was monitored in terms of the color change monitored using a UV spectrophotometer (VARIAN Cary 50 Conc) unit obtained from Agilent Technologies, USA. For the experiments involving catalyst, the withdrawn samples were centrifuged before the spectroscopic analysis and the supernatant was taken for the analysis. Centrifugation was performed for the effective separation of catalyst so as to avoid any interference during the spectroscopic analysis. The calibration curve of the Acid Scarlet 3R dye was used to calculate the concentration of the dye from the recorded absorbance of the dye at wavelength of $505 \mathrm{~nm}$.

\section{Results And Discussion}

\subsection{Effect of operating conditions of ultrasound on particle size}

The effect of the different operating conditions of the ultrasound such as the power of sonication, sonication time, the temperature of the bath and also the mol\% of Fe on the particle size of the catalyst was investigated. The aim of optimizing these operating conditions is to obtain the best catalyst with a smaller particle size and good particle size distribution. Also, the characterization of the catalysts synthesized under optimum conditions using both conventional approach and ultrasound-assisted approach was performed to compare their efficiency. It is expected that a smaller size of the particle could be achieved by the assistance of the ultrasound which can be an effective parameter in deciding the catalyst activity (Shirsath et al. 2013; Neppolian et al. 2008).

\subsubsection{Effect of Power of sonication}


To investigate the effect of the power of sonication on the particle size, the synthesis of the catalyst was carried out at different power of sonication i.e. $80 \mathrm{~W}, 100 \mathrm{~W}, 110 \mathrm{~W}$ and $120 \mathrm{~W}$. The sonication experiment was performed for $30 \mathrm{~min}$ at temperature of $35^{\circ} \mathrm{C}$ and frequency of $22 \mathrm{kHz}$. The percentage of Fe to be doped was considered fixed as $0.4 \mathrm{~mol} \%$. The resultant particle size obtained at different power dissipation values is shown in Fig. 4. It is noticed that as the power of irradiation is increased, the particle size of the catalyst decreases from $608 \mathrm{~nm}$ to $348 \mathrm{~nm}$. The trend shows that high power favors the fragmentation of the particles based on a higher degree of turbulence that tends to inhibit agglomeration or formation of larger particles. Marin et al. (2018) reported similar trend in particle size distribution in silica suspensions. Sivakumar and Gedankan (2004) also reported that an increase in power density increased the extent of particle size reduction of $\mathrm{Fe}(\mathrm{CO})_{5}$. The comparison of results presented in the current work and literature showed that the variation in the power of sonication has a noticeable effect on the particle size of the catalyst and the trends are specific to the system. Considering the results obtained in the present work, the power of $120 \mathrm{~W}$ was fixed as optimum and used for further studies. The smaller size of particles achieved by the ultrasound-assisted process at higher powers could be associated with the fact that high-intensity ultrasound aids in fragmentation of the particle which leads to smaller particles (Sumari et al. 2013; Jordens et al. 2016; Kusters et al. 1993; Bang and Suslick, 2010), though it is noteworthy to understand that there exists an optimum power specific to the system in most cases and establishing the trends for specific system is always important.

\subsubsection{Effect of irradiation time}

Experiments were performed to understand the irradiation time effect on the particle size of $\mathrm{Fe}^{-\mathrm{TiO}_{2}}$ over the range of 15-60 min keeping the power of sonication constant as $120 \mathrm{~W}$ at a bath temperature of $35^{\circ} \mathrm{C}$. The results obtained are plotted in Fig. 5 where it is seen that there is lowering of the particle size up to $30 \mathrm{~min}$ of irradiation and later with an increase in time, the particle size starts increasing. This may be because of the agglomeration of the particles to form bigger particles due to extensive processing beyond the optimum. It is again important that the optimum value will be dependent on the specific system. For example, Neppolian et al. (2008) reported a reduction in crystalline size and also surface area increase for $\mathrm{TiO}_{2}$ when the ultrasound irradiation time was increased from $30 \mathrm{~min}$ to $90 \mathrm{~min}$. Shirsath et al. (2013) also reported that a long time of ultrasound irradiation leads to smaller particle size. Pradhan et al. (2016) reported an increase in particle size at much higher treatment times while synthesizing Mn nanoparticles where lesser particle size was achieved for $15 \mathrm{~min}$ of ultrasound irradiation established as optimum. Ambati and Gogate (2017) also reported a similar trend of existence of optimum irradiation time for the case of $0.8 \mathrm{~mol} \% \mathrm{Fe}$ doped on $\mathrm{TiO}_{2}$. Results on the particle size obtained in the current work suggested that prolonged sonication has beneficial effect on particle size reduction only till $30 \mathrm{~min}$ of sonication and hence this was considered as the optimum sonication time.

\subsubsection{Effect of initial temperature}

To find the effect of the temperature on the catalyst's particle size, the catalyst was synthesized at the optimum power of $120 \mathrm{~W}$ and irradiation time of $30 \mathrm{~min}$ at different temperatures of $35,45,55$ and $65^{\circ} \mathrm{C}$. Though the temperature of the sonicator bath was fixed at the desired value there was a slight elevation 
in the temperature of 2 to $5^{\circ} \mathrm{C}$ due to the cavitation effect. From Fig. 6 , it was observed that there is an increase of particle size from $348 \mathrm{~nm}$ to $516.1 \mathrm{~nm}$ when the initial temperature increased from $35^{\circ} \mathrm{C}$ to $45^{\circ} \mathrm{C}$. When the temperature increases the vapor pressure increases which eventually leads to the formation of a high number of nuclei with low cavitation intensity (Ambati and Gogate, 2017). Patel et al. (2013) also reported the negative effect of the temperature on the particle size reductions attributed to lower cavitational intensity at a higher temperature during their study on cerium zinc molybdate synthesis. It was clearly demonstrated that as the temperature increased from 40 to $80^{\circ} \mathrm{C}$, the particle size increased from $26.3 \mathrm{~nm}$ to $174 \mathrm{~nm}$. It is crucial to notice that the effect of the increase in temperature on the size reduction is dependent on the system. In the current work, no continuous increase in particle size was seen with an increase in the temperature and the particle size reduced marginally from $516.1 \mathrm{~nm}$ at $45^{\circ} \mathrm{C}$ to $502.4 \mathrm{~nm}$ and $478.4 \mathrm{~nm}$, with a subsequent increase in temperature to $55^{\circ} \mathrm{C}$ and $65^{\circ} \mathrm{C}$ respectively. Considering the results obtained in the present work, an initial bath temperature of $35^{\circ} \mathrm{C}$ was considered as the best considering the minimum size obtained that is desirable for better catalytic activity.

\subsubsection{Effect of loading of Fe doped on $\mathrm{TiO}_{2}$}

Experiments were carried out to synthesize $\mathrm{Fe}$ doped $\mathrm{TiO}_{2}$ catalyst with different extents of doping based on the mole percentage of $\mathrm{Fe}$ as $0.2,0.4,0.6,0.8$ and $1 \mathrm{~mol} \%$ under the optimum conditions as power of $120 \mathrm{~W}, 35^{\circ} \mathrm{C}$ as temperature and $30 \mathrm{~min}$ of the irradiation time. The results for particle size depicted in Fig. 7 established that the particle size of the catalyst increased from 319 for $0.2 \mathrm{~mol} \%$ to $575 \mathrm{~nm}$ for 1 $\mathrm{mol} \%$. It was also seen that when the amount of catalyst increased from 0.8 to $1 \mathrm{~mol} \%$, the particle size increase was marginal from $544 \mathrm{~nm}$ to $575 \mathrm{~nm}$. It is expected that there will be a small increase in the size when the metal is doped to $\mathrm{TiO}_{2}$, as the metal controls the inflation in grain size and thereby affects the crystal size (Popa et al. 2010). At higher loadings there is a marginal change, which can be credited to the microstrain effect which results in the formation of a fewer number of recombination spots and active sites eventually leading to a minor difference in particle size (Murashkina et al. 2015). A similar outcome was also reported for $\mathrm{Fe}$ doped $\mathrm{TiO}_{2}$ catalyst synthesized by an ultrasound-assisted sol-gel method where the particle size increased from $185.3 \mathrm{~nm}$ to $351.2 \mathrm{~nm}$ on increasing the Fe load from 0.4 to $2 \mathrm{~mol} \%$ (Ambati and Gogate, 2017). Also in $\mathrm{Mo}$ doped $\mathrm{TiO}_{2}$ catalyst, the crystallite size was reported to increase from 14 to $24 \mathrm{~nm}$ when the Mo loading increased from 0.0625 to $0.25 \mathrm{~mol} \%$ (Khan and Berk, 2014).

As the particle size cannot be the only distinguishing factor for the different doping of $\mathrm{Fe}$ on $\mathrm{TiO}_{2}$ it was decided to use the degradation studies to establish the best performing catalyst. The degradation of 50 ppm Acid Scarlet 3R dye was studied in presence of $16 \mathrm{~W}$ UV light. Figure 8 shows the degradation results for catalysts with different doping \% of $\mathrm{Fe}$. It was seen that $\mathrm{Fe}-\mathrm{TiO}_{2}$ catalyst with 0.4 mole\% doping resulted in maximum degradation of $48.39 \%$ with a corresponding COD reduction of $46.2 \%$. A subsequent increase in the Fe doping amount resulted in lower extents of degradation. The kinetic analysis of the degradation by the catalyst with different Fe doping is shown in Fig. 9 which confirmed the governance of first order kinetic mechaisms. From the graph showing the data for rate constants 
(also tabulated in Table 1), it is clear that 0.4 mol\% of Fe doping has more efficacy in dye degradation reflected by the maximum rate constant. The results depicted in Table 1 in terms of observing best extent of degradation, COD reduction and the kinetic rate constants at optimum doping quantum can be explained by the fact that introducing a small quantity of $\mathrm{Fe}$ to $\mathrm{TiO}_{2}$ below the optimum aids in the lowering of the photogenerated hole-electron recombination rate. When the loading of Fe gets higher, these Fe ions can act as the recombination centers due to which the activity declines slowly. Some of the earlier investigations also showed similar trends, for example, Zhou et al. (2006) showed that a limited amount of $\mathrm{Fe}$ doping to $\mathrm{TiO}_{2}$ with an atomic ratio of $\mathrm{Fe}$ to $\mathrm{Ti}$ as 0.25 demonstrated increased photocatalytic activity. Asiltürk et al. (2009) in their investigation on photocatalytic degradation of Malachite green elucidated that the catalyst with $0.19 \mathrm{wt} \%$ of $\mathrm{Fe}$ doping to $\mathrm{TiO}_{2}$ showed improved photocatalytic activity in comparison to undoped catalyst and catalyst with $4.89 \mathrm{wt} \% \mathrm{Fe}$ doping on $\mathrm{TiO}_{2}$. Nahar et al. (2007) researched the photocatalytic degradation of phenol present in the domestic water and reported that $0.5 \% \mathrm{Fe}$ doped $\mathrm{TiO}_{2}$ as the optimum had a higher degradation capacity.

Table 1

Effect of Fe doping on particle size and Acid Scarlet 3R dye degradation

\begin{tabular}{|llllll|}
\hline $\begin{array}{l}\text { Mole\% Fe doped on } \\
\mathrm{TiO}_{2}(\%)\end{array}$ & $\begin{array}{l}\text { Particle Size } \\
(\mathrm{nm})\end{array}$ & $\begin{array}{l}\text { Degradation } \\
(\%)\end{array}$ & $\begin{array}{l}\text { COD } \\
\text { Reduction } \\
(\%)\end{array}$ & $\begin{array}{l}\text { Pseudo-first-order rate } \\
\text { constant } \\
\left(\mathrm{K} \times 10^{-3}\right)\end{array}$ & $\mathrm{R}^{2}$ \\
\hline 0.2 & & & & $\begin{array}{l}\left(\mathrm{min}^{-1}\right) \\
\end{array}$ & 0.89 \\
\hline 0.4 & 319 & 33.436 & 30.8 & 2.6 & 0.98 \\
\hline 0.6 & 348 & 48.202 & 46.2 & 4.8 & 0.97 \\
\hline 0.8 & 421 & 44.392 & 40.7 & 4.3 & 0.93 \\
\hline 1 & 544 & 39.142 & 38 & 3.2 & 0.9 \\
\hline
\end{tabular}

\subsection{Comparison of conventionally and ultrasonically synthesized catalysts using different analytical techniques}

\subsubsection{Particle size analysis}

The conventionally prepared catalyst (without ultrasound) under the optimized conditions had $1069 \mathrm{~nm}$ of average particle size, with the polydispersity index of 0.251 and the catalyst which is prepared by ultrasound-assisted approach had $348 \mathrm{~nm}$ of average particle size, with a polydispersity index of 0.130 . The graph of intensity versus size obtained for the conventionally and the ultrasonically synthesized catalysts is shown in Fig. 10 (a) and Fig. 10 (b) respectively. From the graphs, we can get that the average particle size of the Fe doped $\mathrm{TiO}_{2}$ catalyst reduces when the catalyst synthesis process is assisted by ultrasound. The observed clear reduction is mainly due to the cavitation effects in terms of the turbulence 
and micro streaming that tend to avoid the agglomeration of the particles as well as drive some extent of particle size reduction.

\subsubsection{X-ray Diffraction Analysis}

To find the phase structure of the prepared Fe doped $\mathrm{TiO}_{2}$ catalysts, wide-angle XRD diffraction pattern analysis was used. The powder samples of the catalysts prepared using the conventional approach (Fig. 11a) and ultrasound assisted approach (Fig. 11b) and were tested. The prominent peaks or the main peaks at $2 \Theta=25.1^{\circ}, 38.4^{\circ}, 47.9^{\circ}, 54.9^{\circ}$ and $62.65^{\circ}$ show the presence of $\mathrm{TiO}_{2}$ in the anatase phase which is predominantly crystalline. These peaks also show that the Fe doping has not affected the anatase phase of $\mathrm{TiO}_{2}$ and hence it can be confirmed that the crystalline structure is not affected by the doping of metal iron. The peak present at $2 \theta=36.7^{\circ}$, plane (004) in the XRD pattern can be attributed to the existence of iron in the form of hematite in the catalysts (Shirsath et al. 2013; Shon et al. 2007, Ganesh et al. 2012). When comparing the figures, intensities of the peaks in the case catalyst prepared by ultrasound are slightly higher and sharper when compared to a catalyst prepared by the conventional approach. These results can be associated with the fact that ultrasound leads to the improved formation of crystalline particles with anatase phase. The crystalline size of the catalyst was also calculated by using the Debye-Scherrer formula using Full Width Half maximal (FWHM) data as per the following equation:

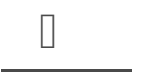

According to the equation, $D$ represents Average Crystal size $(\AA), K$ is the shape factor as $0.9, \lambda$ is the wavelength of incident $x$-ray radiation, $\beta$ represents line width at half maximum intensity, and $\theta$ represents Braggs angle.

The average crystalline size obtained for the Fe doped $\mathrm{TiO}_{2}$ catalyst synthesized by ultrasound-assisted co-precipitation was $98.108 \mathrm{~nm}$ and for the catalyst obtained using the conventional co-precipitation method, it was $170.21 \mathrm{~nm}$. The crystalline size is smaller for the catalyst prepared using the ultrasound approach, which shows the importance and impact of ultrasound in crystalline refinement.

\subsubsection{FTIR Analysis}

FTIR spectral analysis of Fe doped $\mathrm{TiO}_{2}$ catalyst is shown in Fig. 12 (a) for conventionally prepared catalyst and Fig. 12 (b) for the ultrasonically prepared catalyst. In the FTIR spectra, the major absorption band peaks are in the range of $3400 \mathrm{~cm}^{-1}-3450 \mathrm{~cm}^{-1}, 1625 \mathrm{~cm}^{-1}-1630 \mathrm{~cm}^{-1}, 811 \mathrm{~cm}^{-1}-640 \mathrm{~cm}^{-1} \mathrm{and}^{-1}$ $580 \mathrm{~cm}^{-1}-480 \mathrm{~cm}^{-1}$. In the presented spectra obtained, the absorption band between $3420 \mathrm{~cm}^{-1}$ to 3450 $\mathrm{cm}^{-1}$ is assigned to stretched vibrations. Specifically the absorption peak in the region $3400 \mathrm{~cm}^{-1}-3450$ $\mathrm{cm}^{-1}$ is attributed to a weak transmittance band i.e., peaks of $3429.85 \mathrm{~cm}^{-1}$ (US) and $3405.10 \mathrm{~cm}^{-1}(\mathrm{CV})$ that are associated with the stretching vibrations of the $\mathrm{O}-\mathrm{H}$ groups. The absorption band between 1620 
$\mathrm{cm}^{-1}$ to $1640 \mathrm{~cm}^{-1}$ is aligned to bending vibrations whereas that between $520 \mathrm{~cm}^{-1}$ to $580 \mathrm{~cm}^{-1}$ is attributed to stretched vibrations of Ti-O (Shon et al. 2007; Wang et al. 2010; Li et al. 2008). The absorption band peaks between $1625 \mathrm{~cm}^{-1}-1630 \mathrm{~cm}^{-1}$ i.e., $1628.58 \mathrm{~cm}^{-1}$ and $1627.99 \mathrm{~cm}^{-1}$ are associated to the bending vibrations of the $\mathrm{OH}$ radical on the surface of the catalysts which is based on $\mathrm{TiO}_{2}$ (Ganesh et al. 2012; Wang et al. 1999; Litter and Navfo, 1996; Hendrickx and Boardman, 1995; Bally et al. 1998). The band below $800 \mathrm{~cm}^{-1}$ can be due to the Ti-O stretching vibration. The broad band in the region of $500 \mathrm{~cm}^{-1}$ can be due to $\mathrm{Ti}-0-\mathrm{Ti}$ vibrations in the lattice. The anatase phase of $\mathrm{TiO}_{2}$ shows a strong FTIR absorption band at $800 \mathrm{~cm}^{-1}$ to $650 \mathrm{~cm}^{-1}$ regions (Reddy et al. 2002). It is important to note that the results of the present work matches with the literature works on Fe doped $\mathrm{TiO}_{2}$ (Shirsath et al. 2013; Ganesh et al. 2012; Wang et al. 1999; Litter and Navfo, 1996; Bally et al. 1998).

\subsubsection{UV- Visible spectroscopy for band gap analysis}

UV-Visible bad gap analysis was also performed for the catalysts of $\mathrm{TiO}_{2}$ and the Fe doped $\mathrm{TiO}_{2}$ synthesized by the ultrasound-assisted method. The Tauc plot in Fig. 13 demonstrates the estimations of the band gap of both the catalyst. The band gap of the $\mathrm{TiO}_{2}$ catalyst was found to be $3.2 \mathrm{eV}$ whereas the band gap of $\mathrm{Fe}$ doped $\mathrm{TiO}_{2}$ was $2.8 \mathrm{eV}$, which clearly shows that the doping of $\mathrm{Fe}$ to $\mathrm{TiO}_{2}$ has reduced the band gap energy. The band gap of $\mathrm{Fe}$ is known to be $2.6 \mathrm{eV}$, so when this is doped to $\mathrm{TiO}_{2}$ of $3.2 \mathrm{eV}$, the width of the overall band gap of the doped catalyst reduces as compared to the native $\mathrm{TiO}_{2}$. Ganesh et al. (2012) and Ambati and Gogate (2017) also demonstrated similar reports that doping of Fe into $\mathrm{TiO}_{2}$ matrix reduces the band gap.

\subsubsection{BET Analysis}

BET surface analysis for the synthesized catalysts was also carried out employing the nitrogen adsorption technique. Table 2 shows the results for the specific surface area, pore volume and average pore diameter of the catalyst prepared by ultrasound approach and conventional approach. The specific surface area of the Fe doped $\mathrm{TiO}_{2}$ catalyst synthesized by ultrasound-assisted approach was 40.603 $\mathrm{m}^{2} / \mathrm{g}$ and for the conventional approach, it was found to be much lower at $19.413 \mathrm{~m}^{2} / \mathrm{g}$. This trend confirmed that the ultrasound aids in the increase in the surface area. 
Table 2

BET analysis results of $\mathrm{Fe}$ doped $\mathrm{TiO}_{2}$ synthesized by ultrasound-assisted approach and conventional approach.

\begin{tabular}{|llll|}
\hline Catalyst & $\begin{array}{l}\text { Specific Surface Area } \\
\left(\mathrm{m}^{2} / \mathrm{g}\right)\end{array}$ & $\begin{array}{l}\text { Pore Volume } \\
(\mathrm{cc} / \mathrm{g})\end{array}$ & $\begin{array}{l}\text { Average pore diameter } \\
(\mathrm{nm})\end{array}$ \\
\hline $\begin{array}{l}\text { Fe doped } \mathrm{TiO}_{2} \\
\text { (US) }\end{array}$ & 40.603 & 0.091 & 6.104 \\
\hline $\begin{array}{l}\text { Fe doped } \mathrm{TiO}_{2} \\
\text { (CV) }\end{array}$ & 19.413 & 0.043 & 8.196 \\
\hline
\end{tabular}

From the characterization results, it was established that Fe doped $\mathrm{TiO}_{2}$ catalyst with $0.4 \mathrm{~mol} \%$ doping

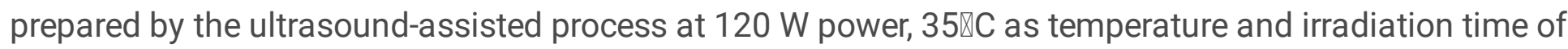
30 min showed best characteristics. This catalyst was taken for the investigation into the degradation of Acid scarlet $3 \mathrm{R}$ dye and comparison of the activity with other catalysts.

\subsection{Comparison of Photocatalytic activity with other catalysts}

Experiments were performed to compare the photocatalytic oxidation efficiencies of the Fe doped $\mathrm{TiO}_{2}$ catalyst with other catalysts such as undoped $\mathrm{TiO}_{2}$ and $\mathrm{Fe}$ doped $\mathrm{TiO}_{2}$ prepared by conventional approach (i.e. without ultrasound) using the system of the degradation of the Acid Scarlet 3R dye. The results are displayed in Table 3 where it could be noticed that the photocatalytic degradation achieved by using US $\mathrm{Fe}-\mathrm{TiO}_{2}$ was $48.2 \%$ with a COD reduction of $46.2 \%$, whereas the that achieved using the CV catalyst was $34 \%$ with a $\mathrm{COD}$ reduction of $23.8 \%$. The undoped $\mathrm{TiO}_{2}$ showed degradation of $28.2 \%$ with COD reduction of $16 \%$ confirming that the Fe doped catalyst had best efficiency. An alike trend was also reported by Sancheti et al. (2018), in their investigation on using $\mathrm{NiO}_{2}-\mathrm{CeO}_{2}$ catalyst prepared ultrasonically and conventionally for the Brilliant green dye degradation, where it was elucidated that the $\mathrm{NiO}_{2}-\mathrm{CeO}_{2}$ catalyst prepared ultrasonically showed degradation of $82 \%$ whereas conventionally prepared catalyst gave only $40 \%$ degradation. Overall, $\mathrm{Fe}$ doped $\mathrm{TiO}_{2}$ catalyst prepared with ultrasound assistance demonstrated the best photocatalytic oxidation. 
Table 3

Effect of different catalyst on the extent of degradation, COD reduction and the pseudo-first-order rate constant by photocatalytic oxidation

\begin{tabular}{|lll|}
\hline Catalyst & Degradation (\%) & COD Reduction (\%) \\
\hline US Fe-TiO & 48.202 & 46.2 \\
\hline CV Fe-TiO $_{2}$ & 33.982 & 23.8 \\
\hline $\mathrm{TiO}_{2}$ & 28.163 & 16 \\
\hline
\end{tabular}

\section{Conclusions}

The Fe doped $\mathrm{TiO}_{2}$ catalyst was synthesized using the co-precipitation method based on the ultrasoundassisted co-precipitation approach and conventional co-precipitation approach. Experimental investigations showed that the catalyst prepared with ultrasonic cavitation using bath-type sonicator had minimum particle size and high specific surface area compared with the catalyst prepared by the conventional approach. The best particle size of the $\mathrm{Fe}$ doped $\mathrm{TiO}_{2}$ catalyst was achieved at the condition of $120 \mathrm{~W}$ power of sonication applied for $30 \mathrm{~min}$ at $35 \otimes \mathrm{C}$ as temperature. Among different doping content of $\mathrm{Fe}, 0.4 \mathrm{~mol} \%$ of $\mathrm{Fe}$ doped $\mathrm{TiO}_{2}$ showed best photocatalytic activity quantified based on the degradation of the selected dye of Acid Scarlet 3R. Fe doped $\mathrm{TiO}_{2}$ catalyst with $0.4 \mathrm{~mol} \%$ of $\mathrm{Fe}$ doping had a particle size of $348 \mathrm{~nm}$ at the optimized condition, whereas the conventionally synthesized catalyst had a particle size of $1069 \mathrm{~nm}$. XRD analysis established the crystallite size of conventionally synthesized catalyst as $170.21 \mathrm{~nm}$, which is about $70 \%$ higher compared to the crystalline size of the catalyst synthesized with ultrasound assistance as $98.108 \mathrm{~nm}$. FTIR spectra showed that the Fe was efficiently doped into the $\mathrm{TiO}_{2}$ matrix. The bandgap energy analysis using UV-Visible spectroscopy proved that the doping of Fe shifted the bandgap energy from $3.2 \mathrm{eV}$ to $2.8 \mathrm{eV}$ indicating better photocatalytic efficiency in the near-UV or visible region. BET analysis of the catalyst showed that the specific surface area was $40.603 \mathrm{~m}^{2} / \mathrm{g}$ for ultrasonically synthesized catalyst whereas, the catalyst prepared by conventional approach showed the lower specific surface area as $19.413 \mathrm{~m}^{2} / \mathrm{g}$ which evidently shows the vital role of ultrasound over increasing the catalyst surface area. From the photocatalytic oxidation experiments based on the degradation of acid Scarlet 3R dye, the catalyst prepared with ultrasound assistance showed $48.2 \%$ degradation whereas the conventionally prepared catalyst showed lower degradation of $34 \%$. The present work clearly establishes that the doping of Fe improves the photocatalytic activity of the catalyst and the ultrasonically synthesized catalyst was more efficient and also yielding better morphological characteristics when compared to the catalyst synthesized by the conventional approach.

\section{Declarations}

Ethics approval and consent to participate: Not applicable 
Consent for publication: Not applicable

Availability of data and materials: Not applicable

Competing interests: The authors declare that they have no competing interests

Funding: No source of funding

Authors' contributions: VM performed the experiments, wrote first draft, PRG interpreted the data and contributed to manuscript finalization. All authors read and approved the final manuscript.

Acknowledgements: Not applicable

\section{References}

Ambati R, Gogate PR (2018) Ultrasound assisted synthesis of iron doped $\mathrm{TiO}_{2}$ catalyst, Ultrason Sonochem 40: 91-100 doi: 10.1016/j.ultsonch.2017.07.002.

Anandan S, Ashokkumar M (2009) Sonochemical synthesis of $\mathrm{Au}^{-\mathrm{TiO}_{2}}$ nanoparticles for the sonophotocatalytic degradation of organic pollutants in aqueous environment. Ultrason Sonochem 16: 316-320 doi: 10.1016/j.ultsonch.2008.10.010.

Asiltürk M, Sayılkan F (2009) Effect of $\mathrm{Fe}^{3+}$ ion doping to $\mathrm{TiO}_{2}$ on the photocatalytic degradation of Malachite Green dye under UV and vis-irradiation. J Photochem Photobiol A Chem 203: 64-71 doi: 10.1016/j.jphotochem.2008.12.021.

Bally AR, Korobeinikova EN, Schmid PE, Levy F, Bussy F (1998) Structural and electrical properties of Fedoped $\mathrm{TiO}_{2}$ thin films. J Phys D: Appl Phys 31:1149-1154

Bang JH, Suslick KS (2010) Applications of ultrasound to the synthesis of nanostructured materials. Adv Mater 22: 1039-1059 doi: 10.1002/adma.200904093.

Barakat MA, Schaeffer H, Hayes G, Ismat-Shah S (2005) Photocatalytic degradation of 2-chlorophenol by Co-doped $\mathrm{TiO}_{2}$ nanoparticles. Appl Catal B Environ 57: 23-30 doi: 10.1016/j.apcatb.2004.10.001.

Bethi B, Sonawane SH, Rohit GS, Holkar CR, Pinjari DV, Pandit AB (2016) Investigation of $\mathrm{TiO}_{2}$ photocatalyst performance for decolourization in the presence of Hydrodynamic cavitation as hybrid AOP. Ultrason Sonochem 28: 150-160 doi: 10.1016/j.ultsonch.2015.07.008.

Chen D, Sharma SK, Mudhoo A (2011) Handbook on applications of ultrasound: Sonochemistry for sustainability. CRC Press, Boca Raton https://doi.org/10.1201/b11012 
Divyapriya G, Nambi IM, Senthilnathan J (2016) Nanocatalysts in Fenton Based Advanced Oxidation Process for Water and Wastewater Treatment. J Bionanoscience 10: 356-368, doi:

10.1166/jbns.2016.1387.

Forgacs E, Cserháti T, Oros G (2004) Removal of synthetic dyes from wastewaters: A review. Environ Int 30:953-971 doi: 10.1016/j.envint.2004.02.001.

Galindo C, Jacques P, Kalt A (2001) Photooxidation of the phenylazonaphthol AO20 on $\mathrm{TiO}_{2}$ : Kinetic and mechanistic investigations. Chemosphere 45: 997-1005 doi: 10.1016/S0045-6535(01)00118-7.

Ganesh I, Kumar PP, Gupta AK, Sekhar PSC, Radha K, Padmanabham G, Sundarajan G (2012) Preparation and characterization of Fe-doped $\mathrm{TiO}_{2}$ powders for solar light response and photocatalytic applications. Process Appl Ceram 6: 21-36 doi: 10.2298/pac1201021g.

Gogate PR, Patil PN (2015) Combined treatment technology based on synergism between hydrodynamic cavitation and advanced oxidation processes. Ultrason Sonochem 25: 60-69 doi:

10.1016/j.ultsonch.2014.08.016.

Gu L, Chen Z, Sun C, Wei B, Yu X, (2010) Photocatalytic degradation of 2 , 4-dichlorophenol using granular activated carbon supported $\mathrm{TiO}_{2}$. Desalination. 263: 107-112 doi: 10.1016/j.desal.2010.06.045.

Hendrickx I, Boardman GD (1995) Pollution Prevention Studies in the Textile Wet Processing Industry. Masters thesis Virginia Tech 1-157.

Hsien YH, Chang CF, Chen YH, Cheng S (2001) Photodegradation of aromatic pollutants in water over $\mathrm{TiO}_{2}$ supported on molecular sieves. Appl Catal B Environ 31: 241-249 doi: 10.1016/S09263373(00)00283-6.

Huang DG, Liao SJ, Zhou WB, Quan SQ, Liu L, He ZJ, Wan JB (2009) Synthesis of samarium- and nitrogen-co-doped $\mathrm{TiO}_{2}$ by modified hydrothermal method and its photocatalytic performance for the degradation of 4-chlorophenol. J Phys Chem Solids, 70: 853-859 doi: 10.1016/j.jpcs.2009.04.005.

Jo WK, Tayade RJ (2014) Recent developments in photocatalytic dye degradation upon irradiation with energy-efficient light-emitting diodes. Cuihua Xuebao/Chinese J Catal 35:1781-1792 doi: 10.1016/S1872-2067(14)60205-9

Jordens J, Appermont T, Gielen B, Van Gerven T, Braeken L (2016) Sonofragmentation: Effect of Ultrasound Frequency and Power on Particle Breakage. Cryst Growth Des 16: 6167-6177 doi: 10.1021/acs.cgd.6b00088.

Khan $\mathrm{H}$, Berk D (2014) Characterization and mechanistic study of $\mathrm{Mo}^{+6} \mathrm{a} \mathrm{V}^{+5}$ codoped $\mathrm{TiO}_{2}$ as a photocatalyst. J Photochem Photobiol A Chem 294: 96-109 doi: 10.1016/j.jphotochem.2014.08.007. 
Kočí K, Matějů K, Obalová L, Krejčíková S, Lacný Z, Plachá D, Čapek L, Hospodková A, Šolcová O (2010) Effect of silver doping on the $\mathrm{TiO}_{2}$ for photocatalytic reduction of $\mathrm{CO}_{2}$. Appl Catal B Environ 96: 239244, doi: 10.1016/j.apcatb.2010.02.030.

Kusters KA, Pratsinis SE, Thoma SG, Smith DM (1993) Ultrasonic fragmentation of agglomerate powders. Chem Eng Sci 48: 4119-4127 doi: 10.1016/0009-2509(93)80258-R.

Li H, Liu G, Chen S, Liu Q (2010) Novel Fe doped mesoporous $\mathrm{TiO}_{2}$ microspheres: Ultrasonic-hydrothermal synthesis, characterization, and photocatalytic properties. Phys E Low-Dimensional Syst Nanostructures 42: 1844-1849 doi: 10.1016/j.physe.2010.02.008.

Li Y, Xie C, Peng S, Lu G, Li S, (1999) Eosin Y-sensitized nitrogen-doped $\mathrm{TiO}_{2}$ for efficient visible light photocatalytic hydrogen evolution. J Mol Catal A Chem 282: 117-123 doi:

10.1016/j.molcata.2007.12.005.

Litter MI, Navfo JA, (1996) Photocatalytic properties of iron-doped titania semiconductors, J. Photochem Photobiol 98: 171-181,.

Mahvi AH, Ghanbarian M, Nasseri S, Khairi A (2009) Mineralization and discoloration of textile wastewater by $\mathrm{TiO}_{2}$ nanoparticles. Desalination. 239: 309-316, doi: 10.1016/j.desal.2008.04.002.

Marín RRR, Babick F, Lindner GG, Wiemann M, Stintz M (2018) Effects of sample preparation on particle size distributions of different types of silica in suspensions, Nanomaterials 8: 454 doi: 10.3390/nano8070454.

Moholkar VS, Sable SP, Pandit AB (2000) Mapping the cavitation intensity in an ultrasonic bath using the acoustic emission. AIChE J 46: 684-694 doi: 10.1002/aic.690460404.

Murashkina AA, Murzin PD, Rudakova AV, Ryabchuk VK, Emeline AV, Bahnemann DW (2015) Influence of the Dopant Concentration on the Photocatalytic Activity: Al-Doped $\mathrm{TiO}_{2}$. J Phys Chem, 119: 24695 24703 doi: $10.1021 /$ acs.jpcc.5b06252.

Musmarra D, Prisciandaro M, Capocelli M, Karatza D, lovino P, Canzano S, Lancia A (2016) Degradation of ibuprofen by hydrodynamic cavitation: Reaction pathways and effect of operational parameters. Ultrason Sonochem 29:76-83 doi: 10.1016/j.ultsonch.2015.09.002.

Nahar MS, Hasegawa K, Kagaya S (2007) Comparative assessment of the efficiency of Fe- doped $\mathrm{TiO}_{2}$ prepared by two doping methods and photocatalytic degradation of phenol in domestic water suspensions. Sci Technol Adv Mater 8: 286-291 doi: 10.1016/j.stam.2007.04.005.

Neppolian B, Wang Q, Jung H, Choi H (2008) Ultrasonic-assisted sol-gel method of preparation of $\mathrm{TiO}_{2}$ nano-particles: Characterization, properties and 4-chlorophenol removal application. Ultrason Sonochem 15: 649-658 doi: 10.1016/j.ultsonch.2007.09.014. 
Patel MA, Bhanvase BA, Sonawane SH (2013) Production of cerium zinc molybdate nano pigment by innovative ultrasound assisted approach. Ultrason Sonochem 20: 906-913 doi:

10.1016/j.ultsonch.2012.11.008.

Peng Y, Huang G, Huang W (2012) Visible-light absorption and photocatalytic activity of Cr-doped $\mathrm{TiO}_{2}$ nanocrystal films. Adv Powder Technol 23: 8-12 doi: 10.1016/j.apt.2010.11.006.

Popa M, Indrea E, Pascuta P, Cosoveanu V, Popescu I, Danciu V (2010) Fe, Ce and Cu influence on morpho-structural and photocatalytic properties of $\mathrm{TiO}_{2}$ aerogels. Rev Roum Chim 55: 369-375

Pradhan S, Hedberg J, Blomberg E, Wold S, Wallinder IO (2016) Effect of sonication on particle dispersion, administered dose and metal release of non-functionalized, non-inert metal nanoparticles. J Nanoparticle Res 18:1-14 doi: 10.1007/s11051-016-3597-5.

Priyaragini S, Veena S, Swetha D, Karthik L, Kumar G, Bhaskara Rao KV (2014) Evaluating the effectiveness of marine actinobacterial extract and its mediated titanium dioxide nanoparticles in the degradation of azo dyes. J Environ Sci (China) 26: 775-782 doi: 10.1016/S1001-0742(13)60470-2.

Qi XH, Wang ZH, Zhuang YY, Yu Y, Li JL (2005) Study on the photocatalysis performance and degradation kinetics of X-3B over modified titanium dioxide. J Hazard Mater 118: 219-225 doi: 10.1016/j.jhazmat.2004.11.007.

Ranjit KT, Viswanathan B (1997) Synthesis, characterization and photocatalytic properties of iron-doped $\mathrm{TiO}_{2}$ catalysts. J Photochem Photobiol A Chem 108: 79-84 doi: 10.1016/S1010-6030(97)00005-1.

Rao PR, Rathod VK (2015) Mapping study of an ultrasonic bath for the extraction of andrographolide from Andrographis paniculata using ultrasound. Ind Crops Prod 66: 312-318 doi:

10.1016/j.indcrop.2014.11.046.

Rauf MA, Meetani MA, Hisaindee S (2011) An overview on the photocatalytic degradation of azo dyes in the presence of $\mathrm{TiO}_{2}$ doped with selective transition metals. Desalination 276: 13-27 doi:

10.1016/j.desal.2011.03.071.

Reddy BM, Sreekanth PM, Reddy EP (2002) Surface Characterization of $\mathrm{La}_{2} \mathrm{O}_{3}-\mathrm{TiO}_{2}$ and $\mathrm{V}_{2} \mathrm{O}_{5} / \mathrm{La}_{2} \mathrm{O}_{3}-\mathrm{TiO}_{2}$ Catalysts Benjaram J Phys Chem 106: 5695-5700

Reddy DR, Dinesh GK, Anandan S, Sivasankar T (2016) Sonophotocatalytic treatment of Naphthol Blue Black dye and real textile wastewater using synthesized Fe doped $\mathrm{TiO}_{2}$, Chem Eng Process 99: 10-18 doi: 10.1016/j.cep.2015.10.019.

Sancheti SV, Saini C, Ambati R, Gogate PR (2018) Synthesis of ultrasound assisted nanostuctured photocatalyst ( $\mathrm{NiO}$ supported over $\mathrm{CeO}_{2}$ ) and its application for photocatalytic as well as sonocatalytic dye degradation. Catal Today 300:50-57 doi: 10.1016/j.cattod.2017.02.047 
Shirsath SR, Pinjari DV, Gogate PR, Sonawane SH, Pandit AB (2013) Ultrasound assisted synthesis of doped $\mathrm{TiO}_{2}$ nano-particles: Characterization and comparison of effectiveness for photocatalytic oxidation of dyestuff effluent. Ultrason Sonochem 20: 277-286 doi: 10.1016/j.ultsonch.2012.05.015.

Shon HK, Park HJ, Vigneswaran S, Cho DL (2007) Development of a novel method to prepare Fe- and Aldoped titanium dioxide $\left(\mathrm{TiO}_{2}\right)$ from wastewater. J Ind Eng Chem 15:476-482 https://doi.org/10.1016/j.jiec.2009.01.004

Sivakumar M, Gedanken A (2004) Insights into the sonochemical decomposition of $\mathrm{Fe}(\mathrm{CO})_{5}$ : Theoretical and experimental understanding of the role of molar concentration and power density on the reaction yield. Ultrason Sonochem 11: 373-378 doi: 10.1016/j.ultsonch.2003.08.002.

Sood S, Umar A, Mehta SK, Kansal SK (2015) Highly effective Fe-doped $\mathrm{TiO}_{2}$ nanoparticles photocatalysts for visible-light driven photocatalytic degradation of toxic organic compounds. J Colloid Interface Sci 450: 213-223 doi: 10.1016/j.jcis.2015.03.018.

Sumari S, Roesyadi A, Sumarno S (2013) Effects of ultrasound on the morphology, particle size, crystallinity, and crystallite size of cellulose. Sci Study Res Chem Chem Eng 14: 229-239.

Tong T, Zhang J, Tian B, Chen F, He D (2008) Preparation of $\mathrm{Fe}^{3+}$-doped $\mathrm{TiO}_{2}$ catalysts by controlled hydrolysis of titanium alkoxide and study on their photocatalytic activity for methyl orange degradation. J Hazard Mater 155: 572-579 doi: 10.1016/j.jhazmat.2007.11.106.

Vautier M, Guillard C, Herrmann JM (2001) Photocatalytic degradation of dyes in water: Case study of indigo and of indigo carmine. J Catal 201: 46-59 doi: 10.1006/jcat.2001.3232.

Wang J, Lv Y, Zhang L, Liu B, Jiang R, Han G (2010) Sonocatalytic degradation of organic dyes and comparison of catalytic activities of $\mathrm{CeO}_{2} / \mathrm{TiO}_{2}, \mathrm{SnO}_{2} / \mathrm{TiO}_{2}$ and $\mathrm{ZrO}_{2} / \mathrm{TiO}_{2}$ composites under ultrasonic irradiation. Ultrason. Sonochem. 17: 642-648 doi: 10.1016/j.ultsonch.2009.12.016.

Wang Y, Cheng H, Hao Y, Ma J, Li W (1999) Preparation, characterization and photoelectrochemical behaviors of $\mathrm{Fe}$ (III)-doped $\mathrm{TiO}_{2}$ nanoparticles. J Mater Sci, 4: 3721-3729.

Zhou M, Yu J, Cheng B (2006) Effects of Fe-doping on the photocatalytic activity of mesoporous $\mathrm{TiO}_{2}$ powders prepared by an ultrasonic method. J Hazard Mater 137: 1838-1847 doi:

10.1016/j.jhazmat.2006.05.028.

\section{Figures}




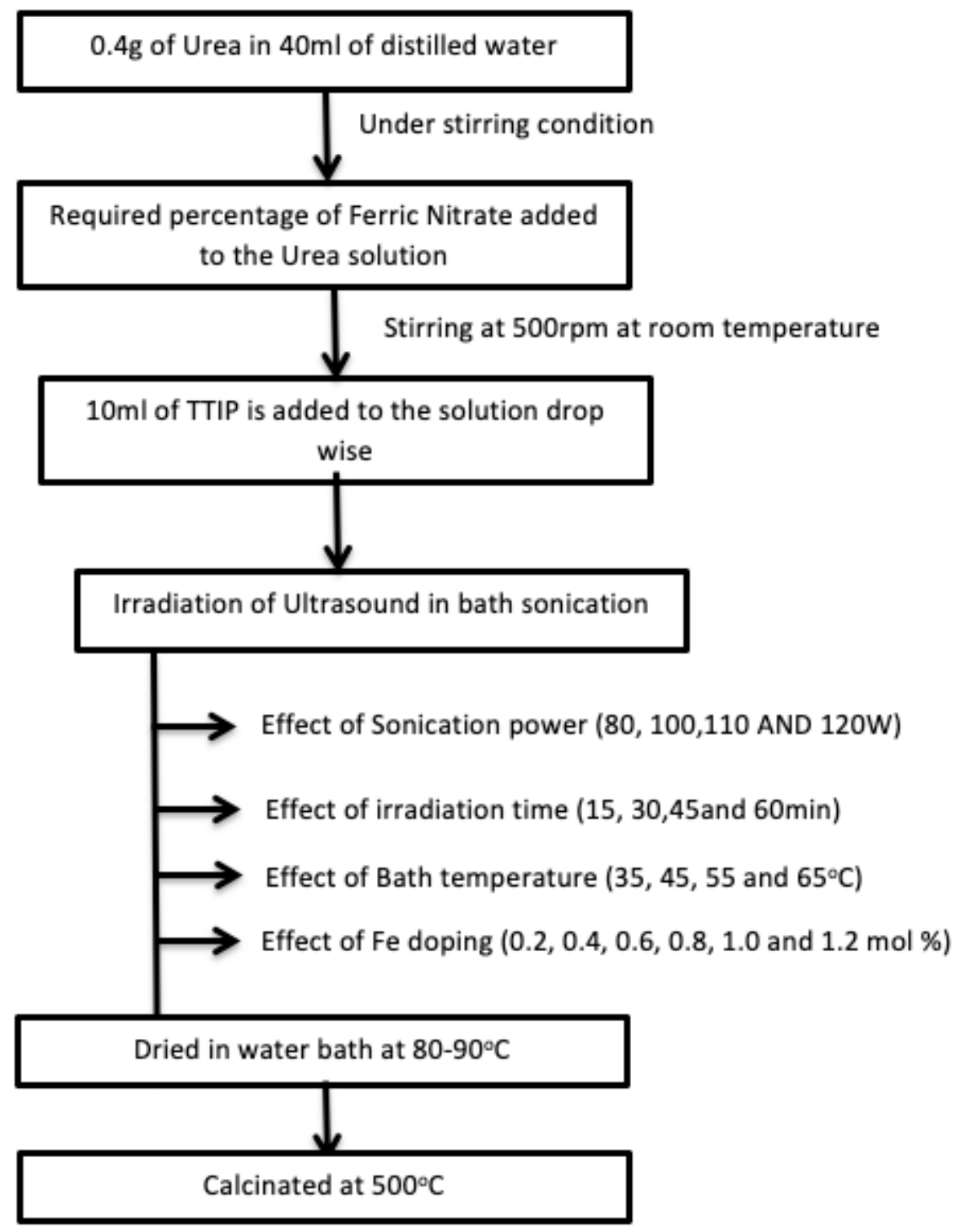

Figure 1

Flow chart for the catalyst synthesis process 


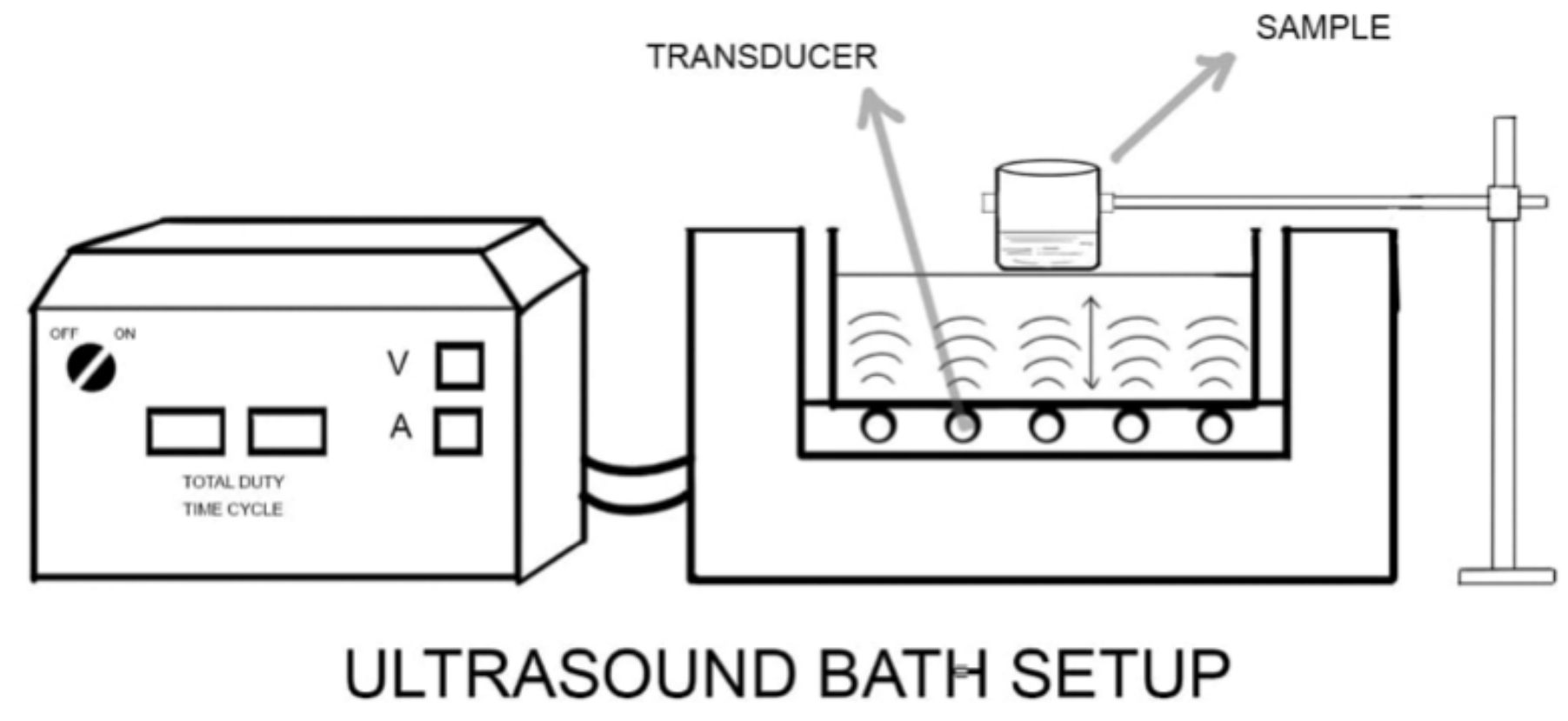

Figure 2

Ultrasonic bath setup for the ultrasound-assisted catalyst synthesis process

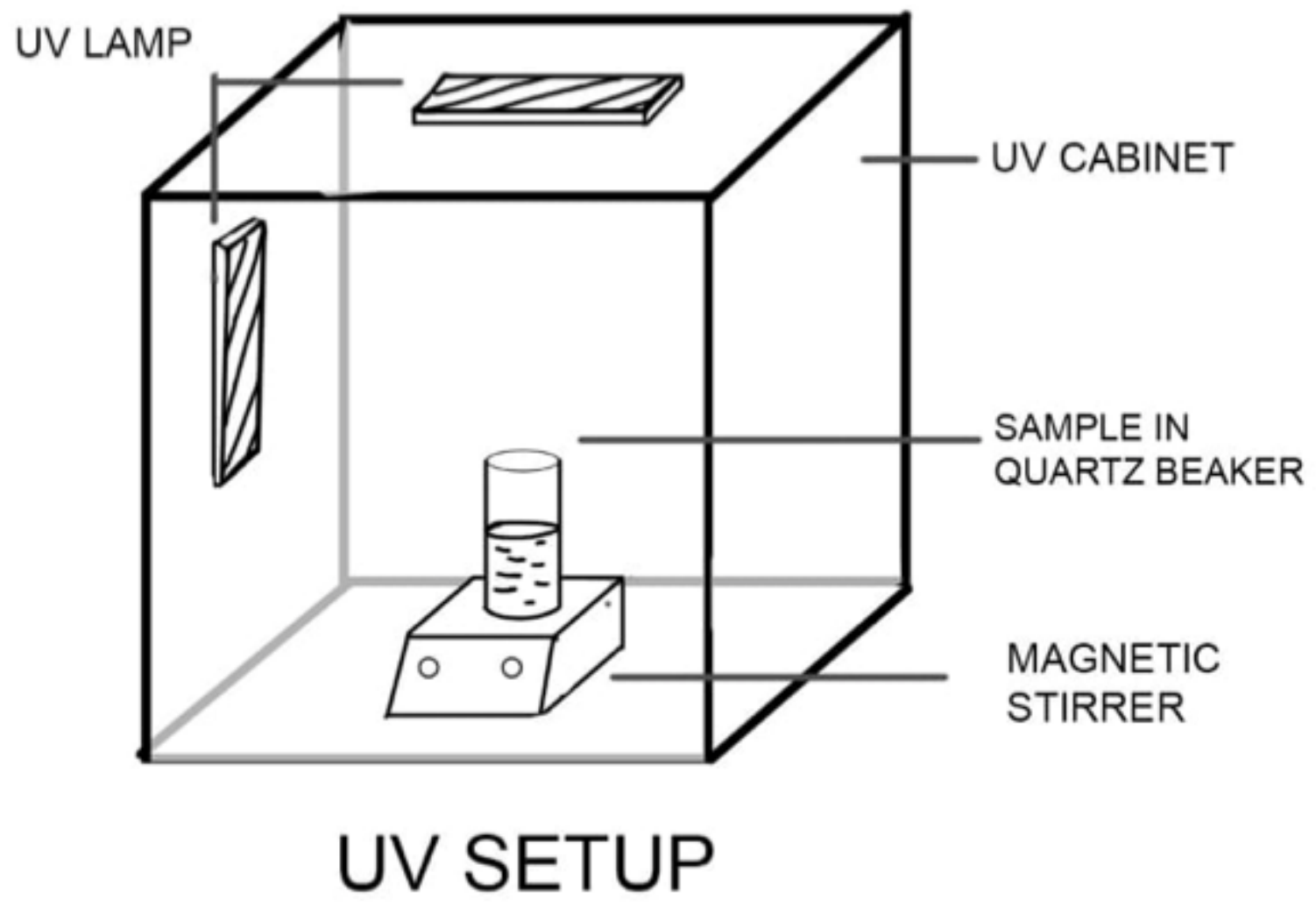

Figure 3 
UV chamber set up for the photocatalytic treatment

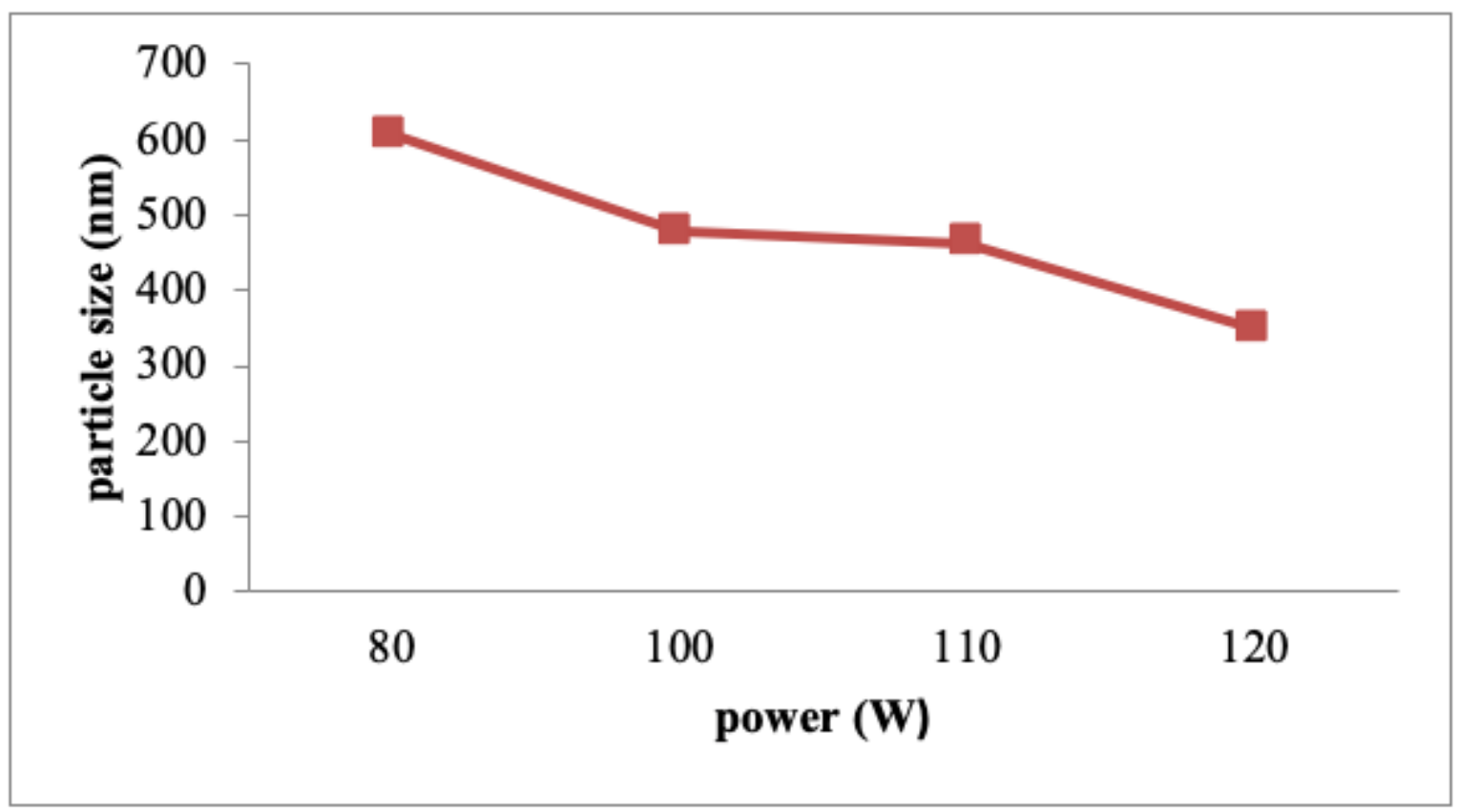

Figure 4

Effect of power of ultrasound on particle size of catalyst

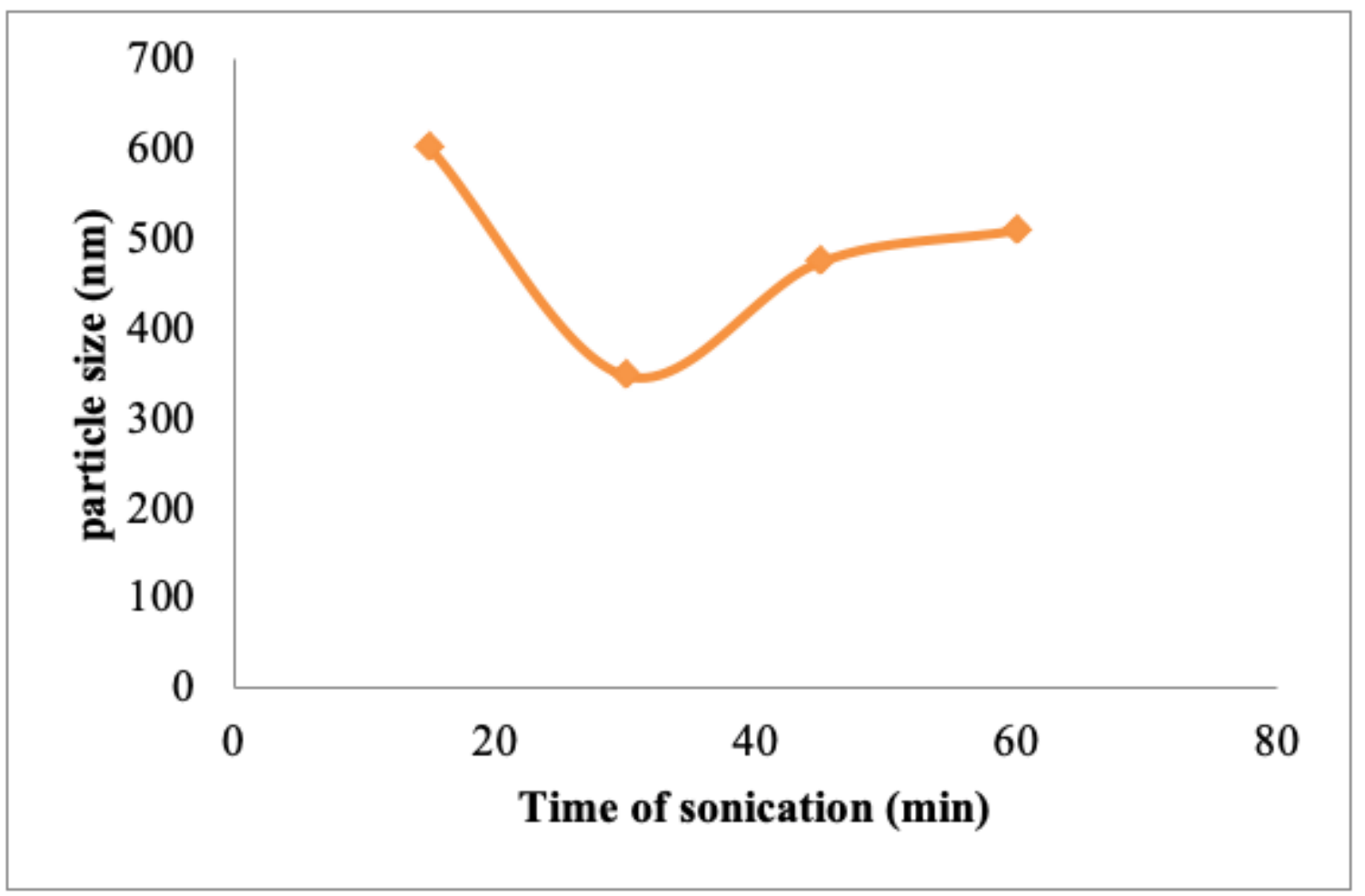

Figure 5 
Effect of Irradiation time on particle size of catalyst

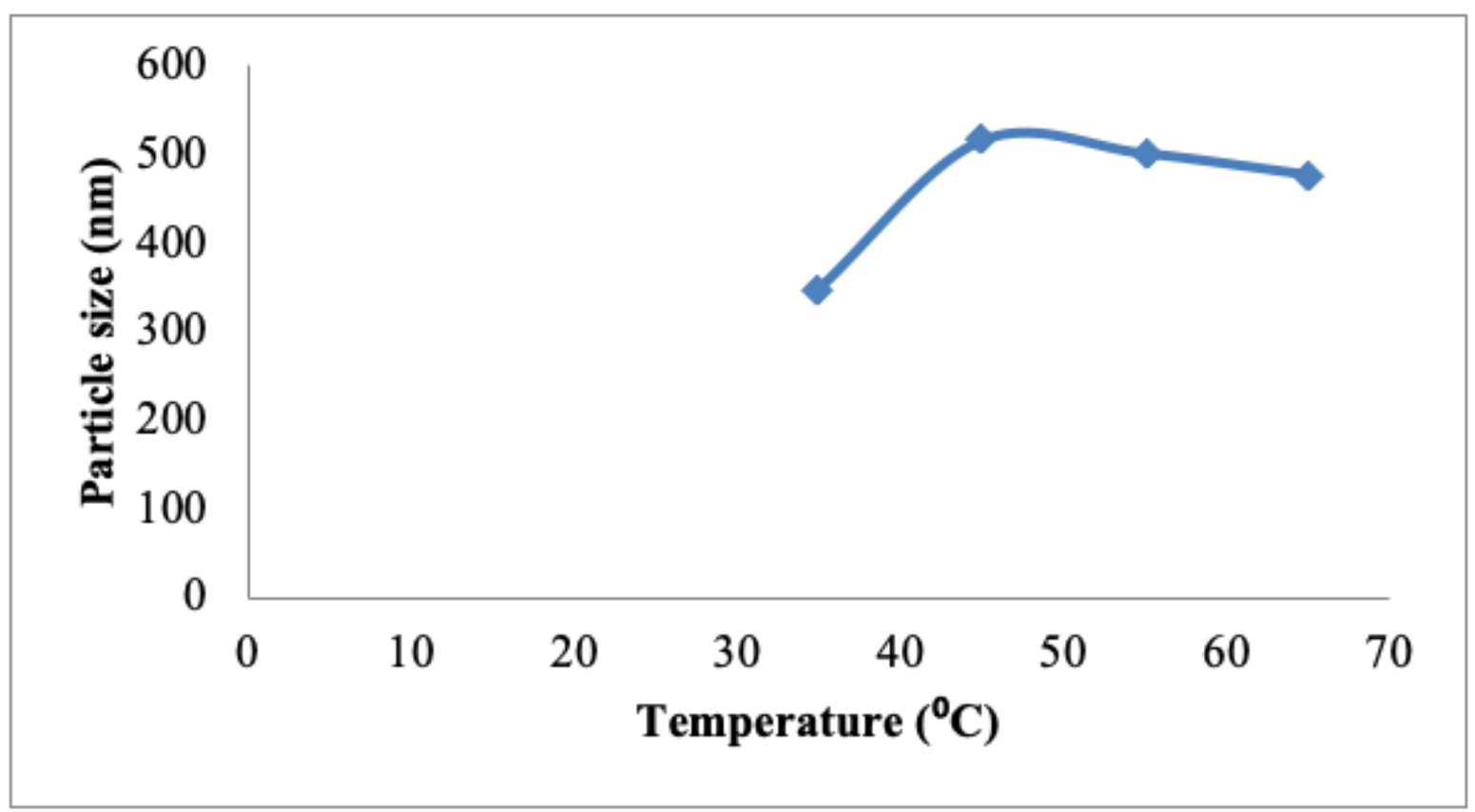

Figure 6

Effect of Temperature on particle size of catalyst

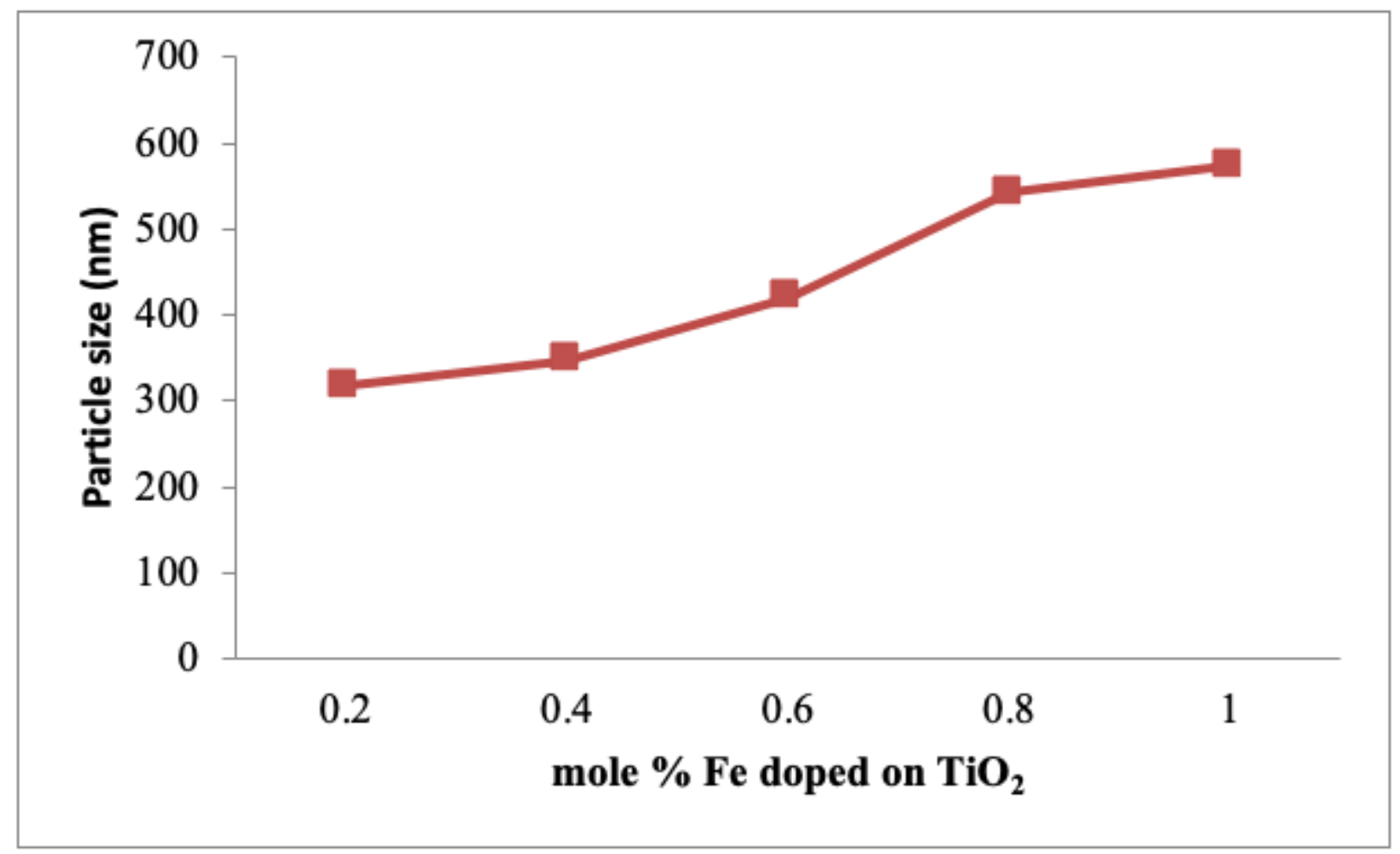

Figure 7 


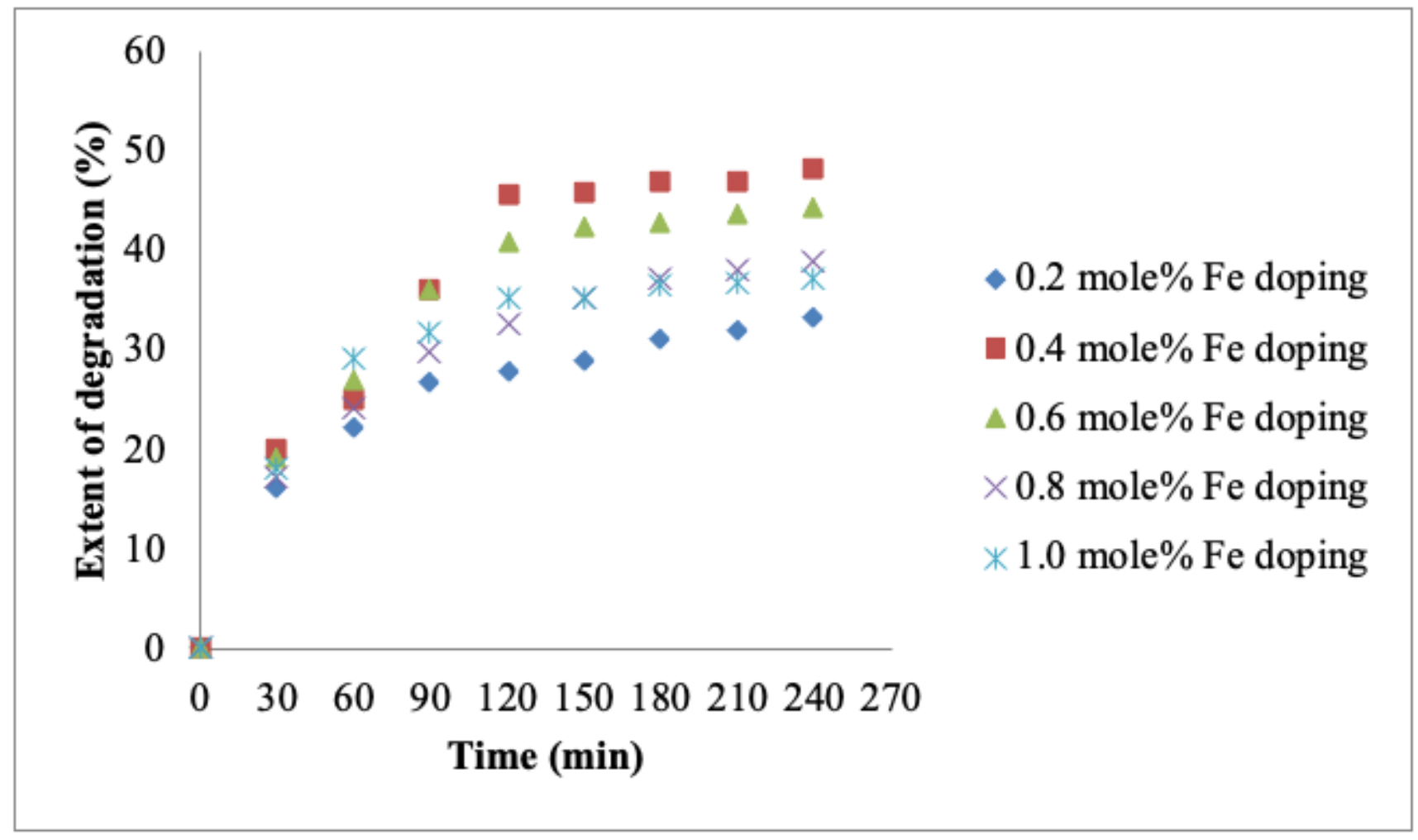

Figure 8

Effect of Fe doping content in TiO2 on the degradation of Acid Scarlet 3R dye

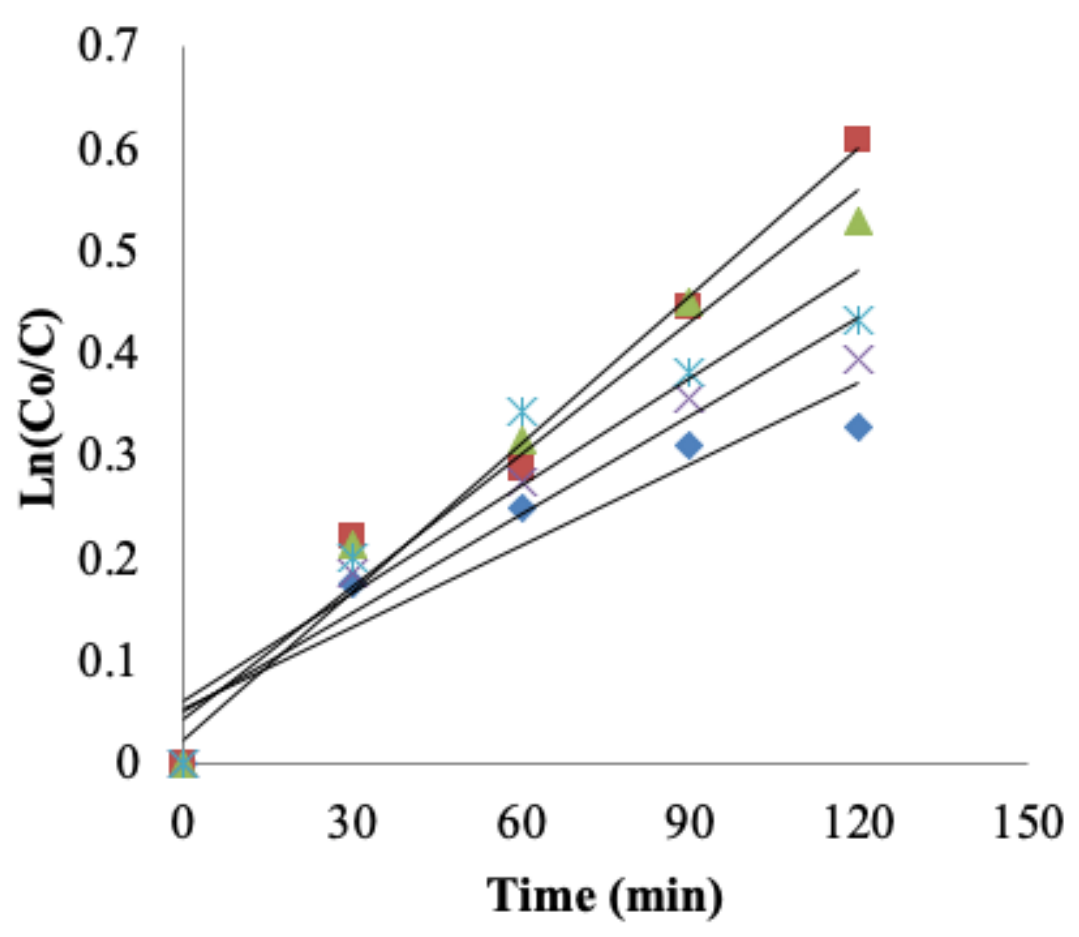

$\checkmark .2$ mole $\%$ Fe doping

0.4 mole $\%$ Fe doping

$\triangle 0.6$ mole $\%$ Fe doping

$\times 0.8$ mole $\%$ Fe doping

$* 1.0$ mole $\%$ Fe doping 
Figure 9

Kinetics of Acid Scarlet 3R degradation at different Fe doping content on TiO2

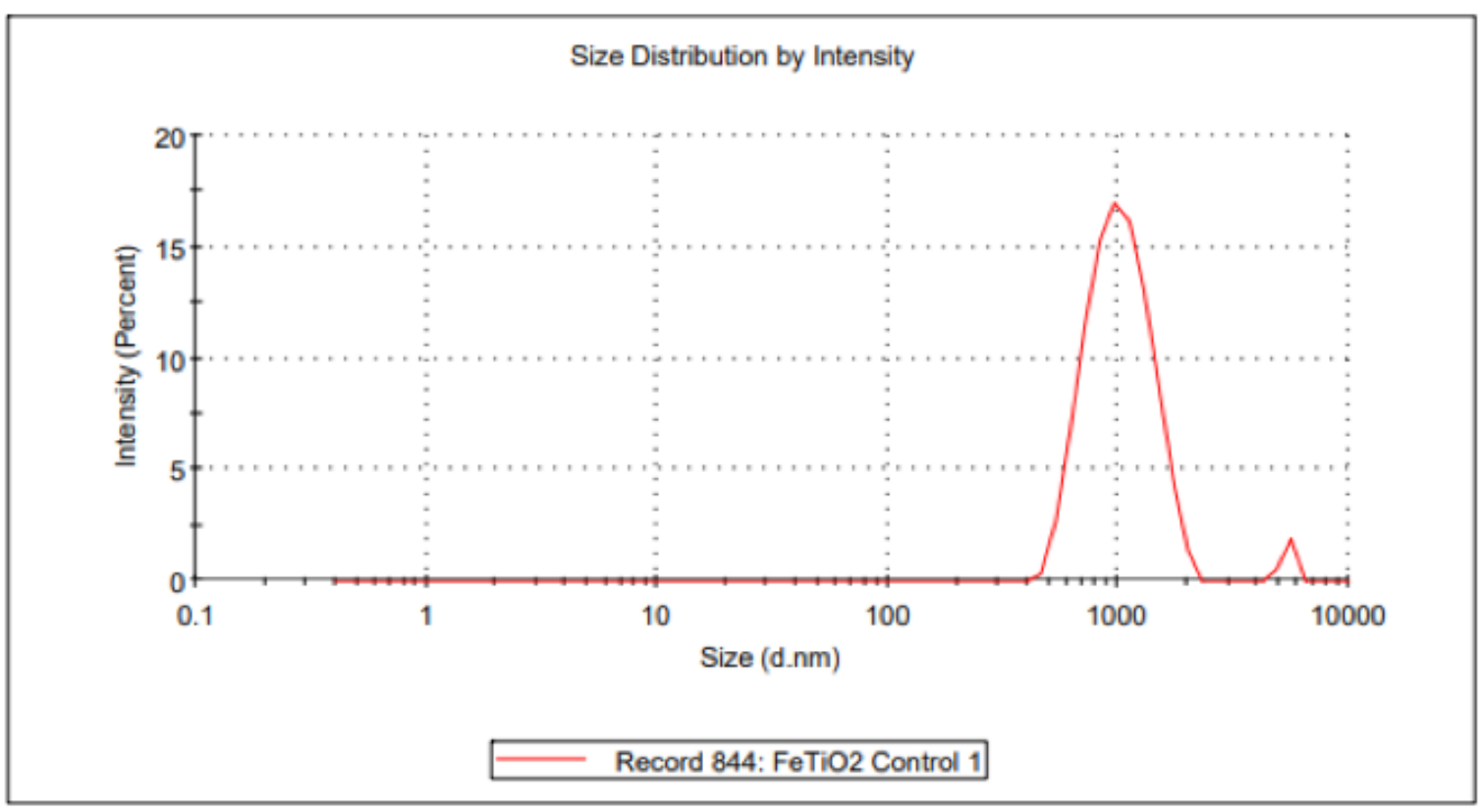

(a)

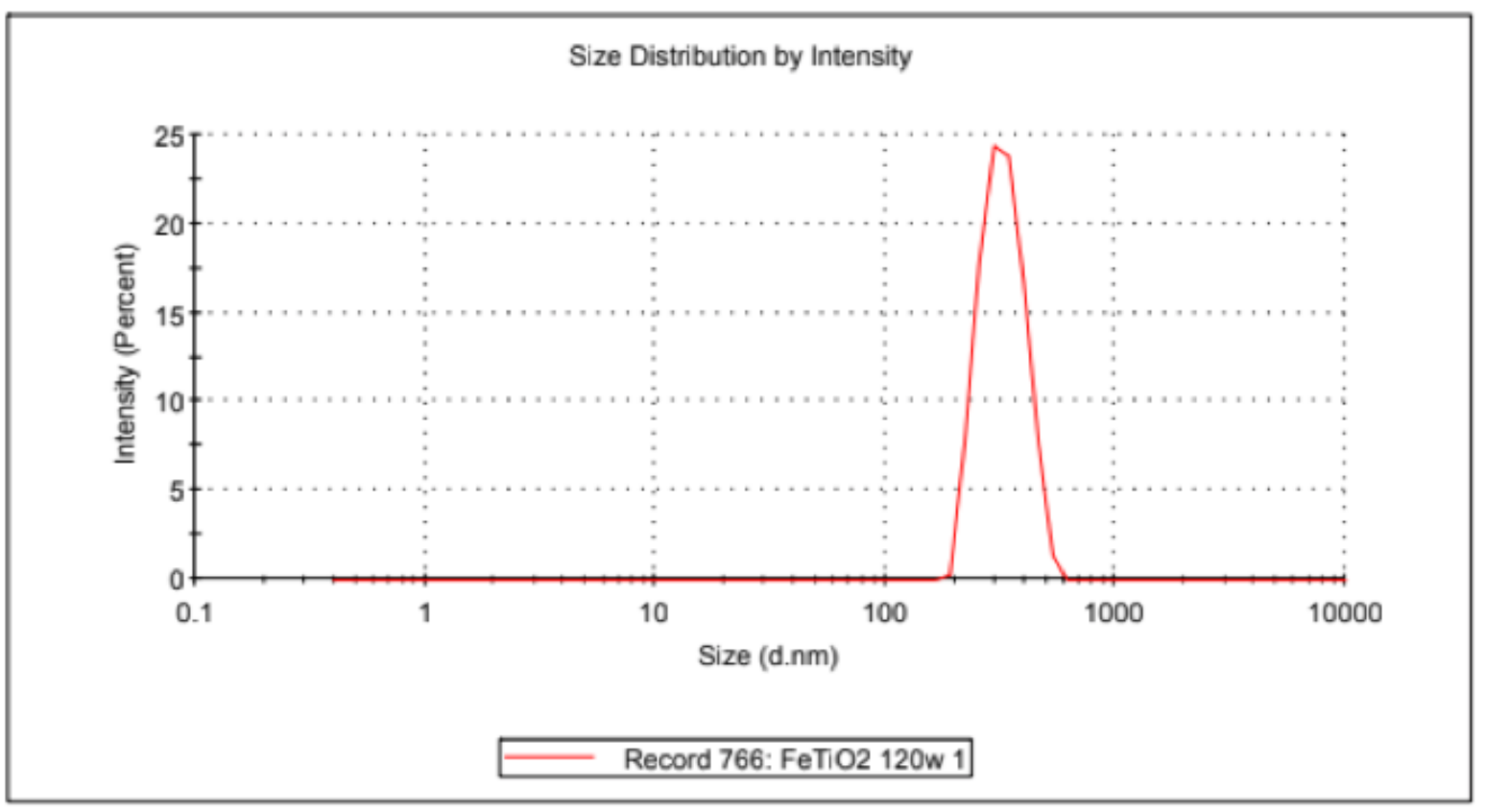

(b)

\section{Figure 10}

The particle size distribution of Fe doped TiO2 catalyst (a) Synthesized by conventional approach at 0.4 mol\% Fe doping (b) Synthesized by ultrasound-assisted approach at 0.4 mol\% Fe doping, $120 \mathrm{~W}$ of 
power, $35^{\circ} \mathrm{C}$ and $30 \mathrm{~min}$

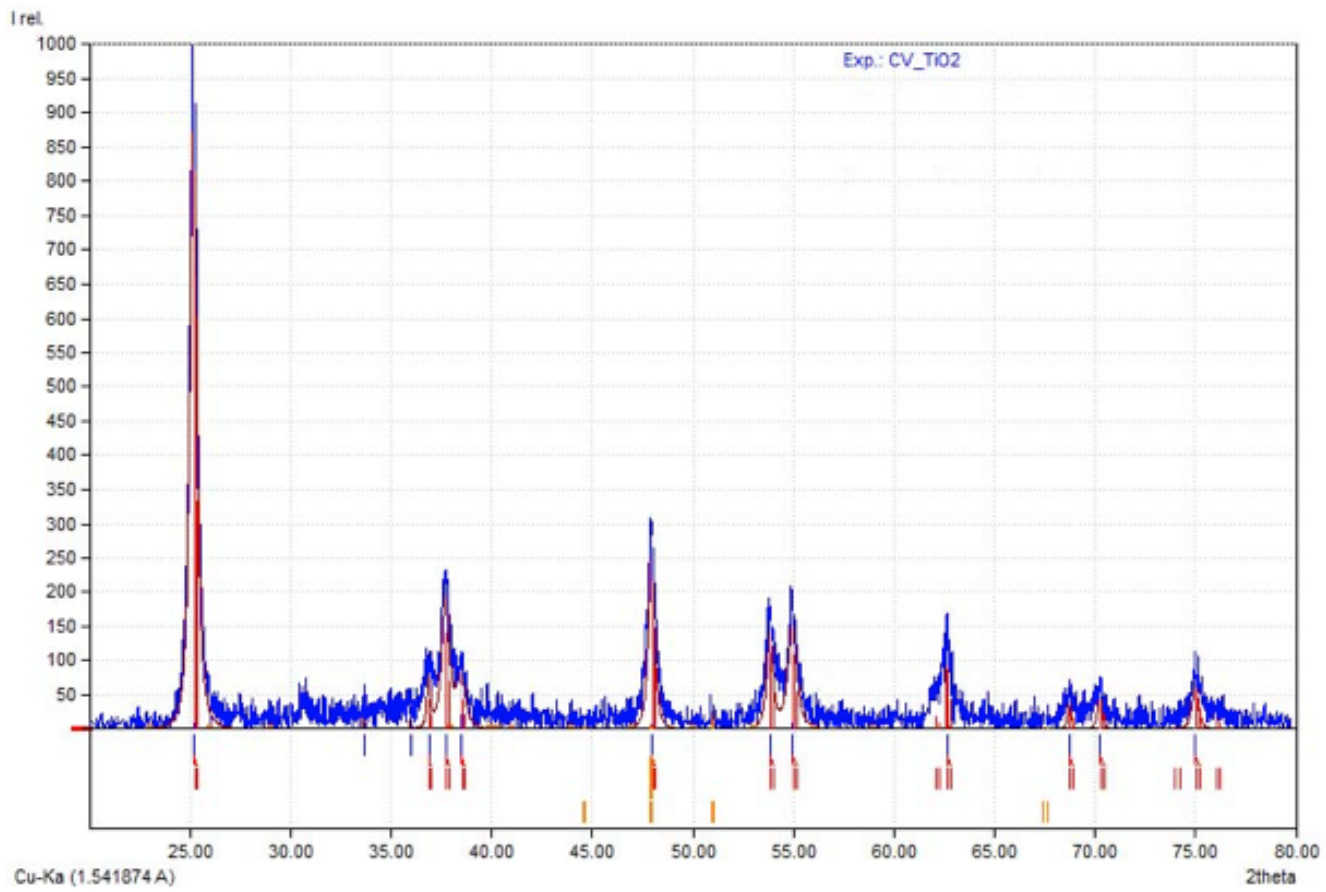

(a)

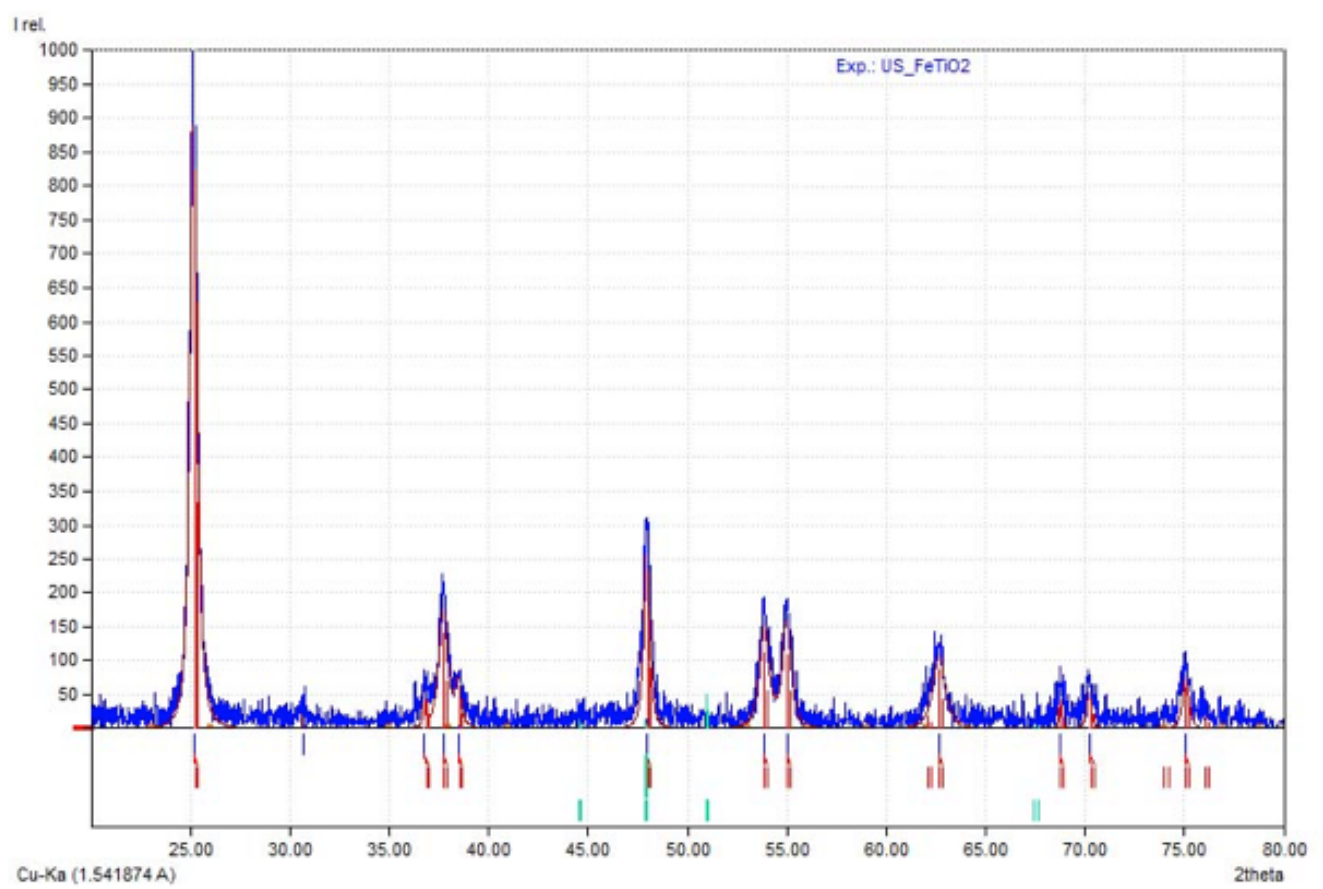

(b)

Figure 11

XRD pattern for the Fe doped TiO2 catalyst (a) Synthesized by conventional approach with $0.4 \mathrm{~mol} \%$ of Fe doping. (b) Synthesized by ultrasound-assisted approach with $0.4 \mathrm{~mol} \%$ of Fe at optimum conditions of $120 \mathrm{~W}$ power, $35 \square \mathrm{C}$ and $30 \mathrm{~min}$ 


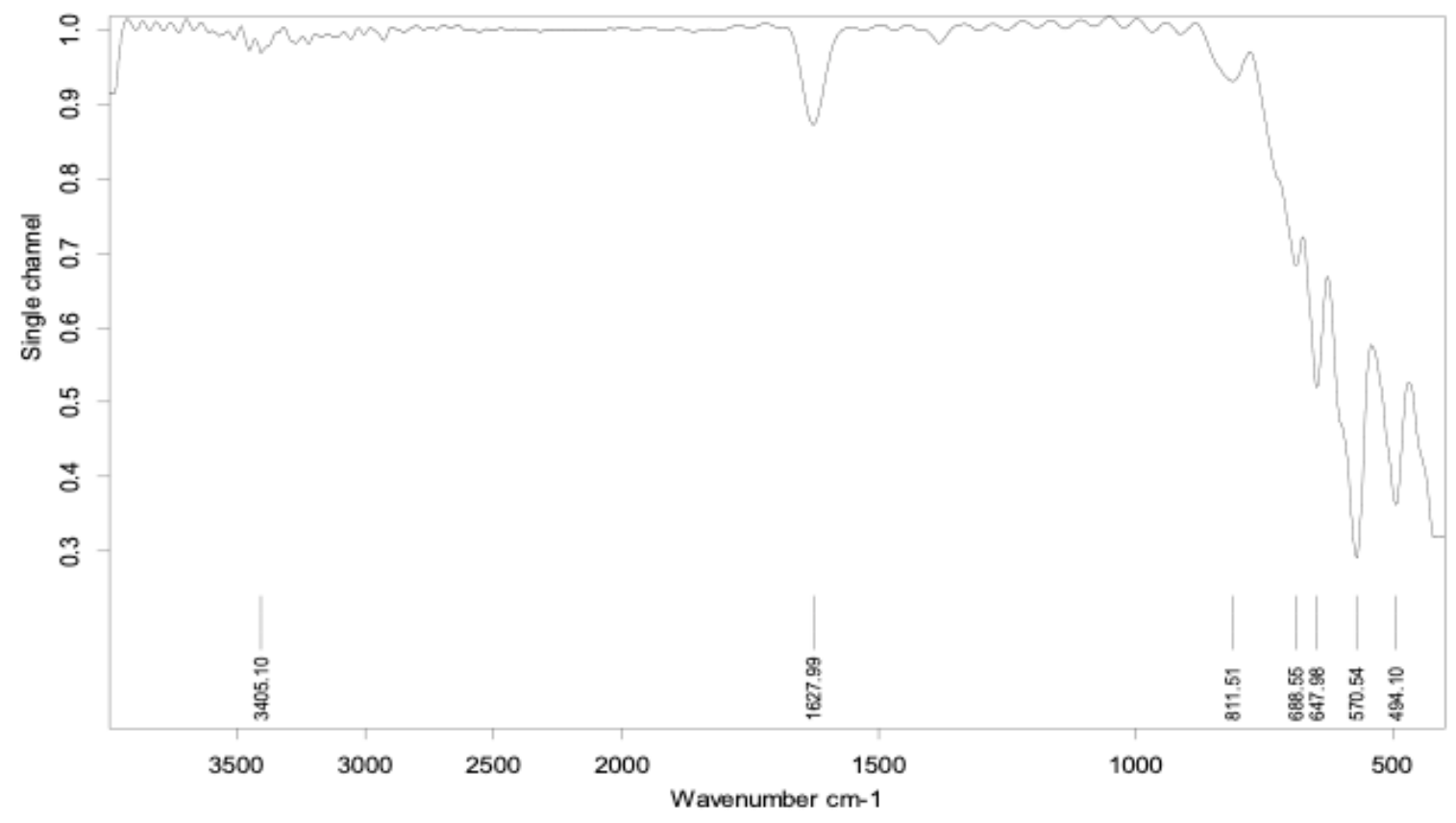

(a)

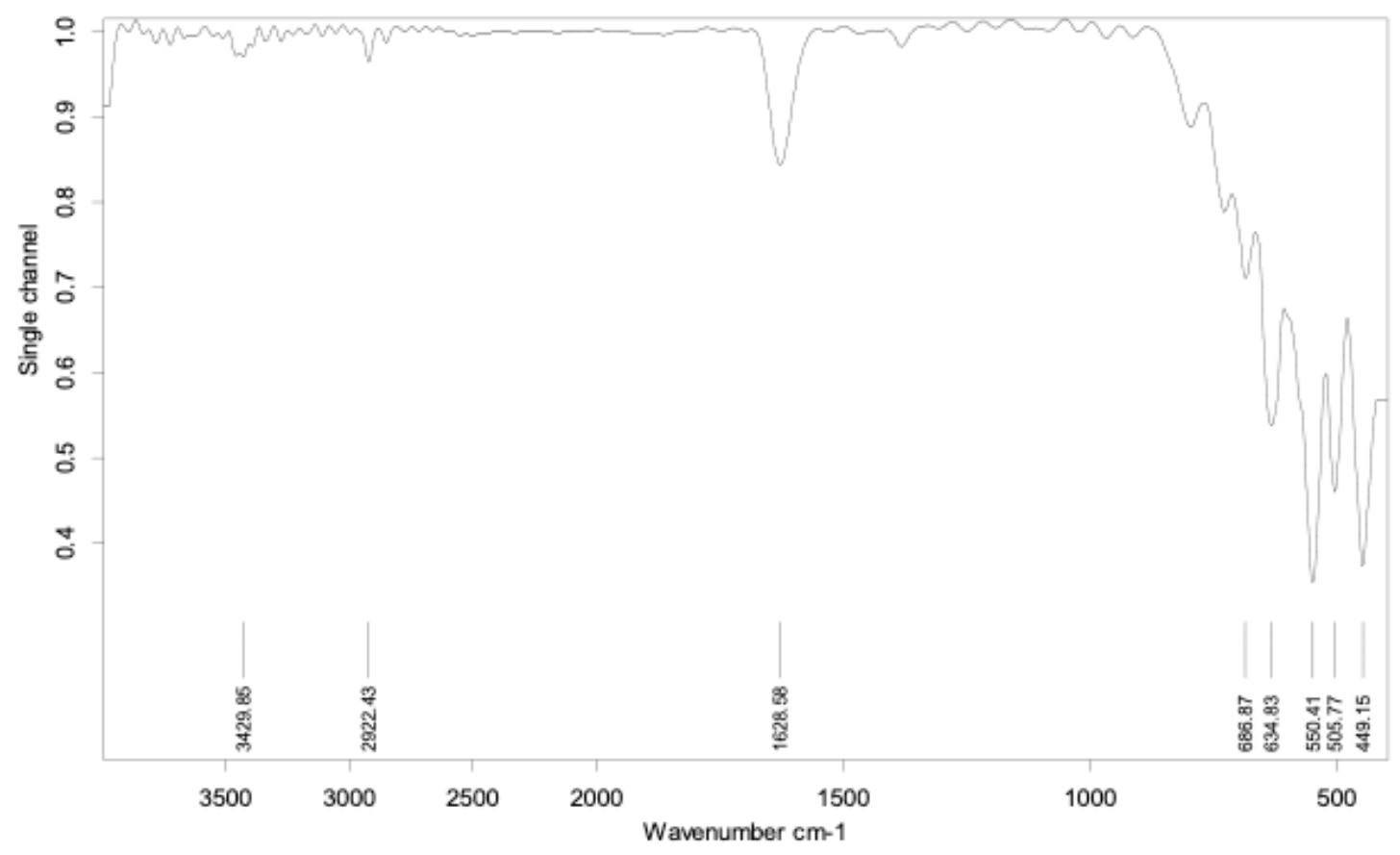

(b)

Figure 12

FTIR spectra of Fe doped TiO2 catalyst (a) Synthesised by conventional approach with $0.4 \mathrm{~mol} \% \mathrm{Fe}$. (b) Synthesized by ultrasound-assisted approach with $0.4 \mathrm{~mol} \%$ of Fe at optimum conditions of $120 \mathrm{~W}$ power, $35 \square \mathrm{C}$ and $30 \mathrm{~min}$ 


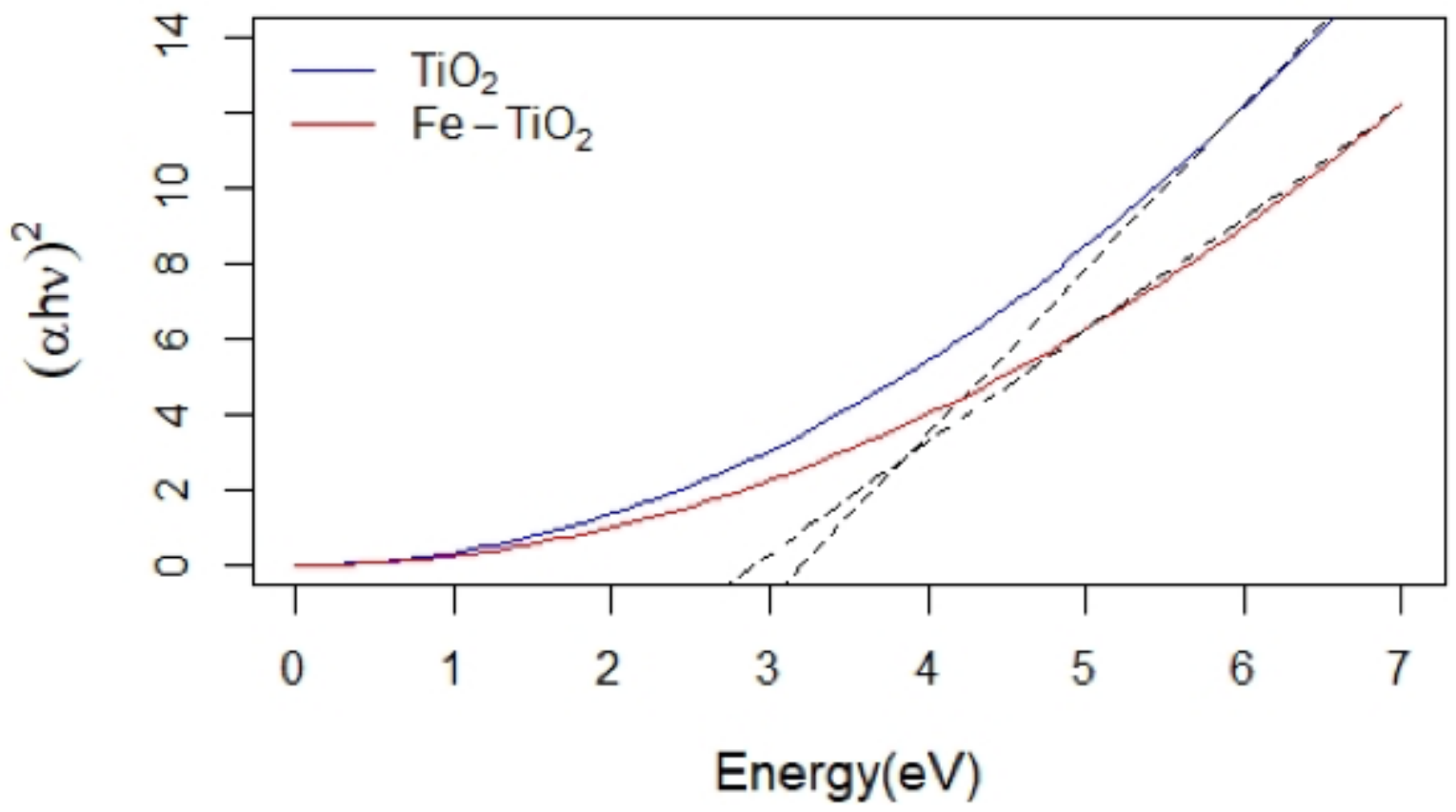

Figure 13

Tauc plot of UV-Visible spectra of TiO2 and Fe doped TiO2 catalyst prepared using ultrasound-assisted synthesis with $0.4 \mathrm{~mol} \%$ doping of Fe at optimum conditions 